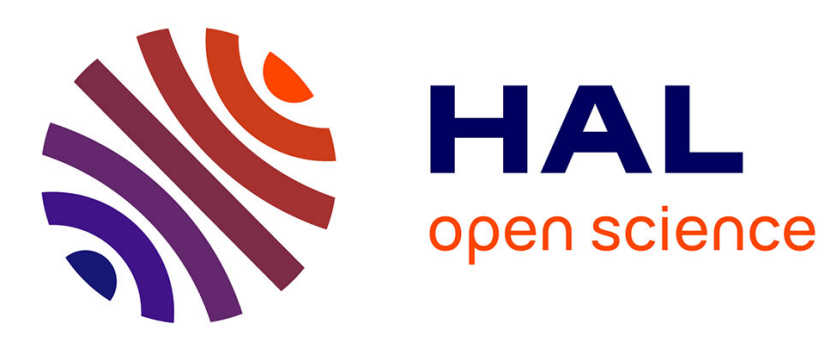

\title{
Price and network dynamics in the European carbon market
}

\author{
Andreas Karpf, Antoine Mandel, Stefano Battiston
}

\section{To cite this version:}

Andreas Karpf, Antoine Mandel, Stefano Battiston. Price and network dynamics in the European carbon market. Journal of Economic Behavior and Organization, 2018, 153, pp.103-122. 10.1016/j.jebo.2018.06.019 . halshs-01905985

\section{HAL Id: halshs-01905985 \\ https://shs.hal.science/halshs-01905985}

Submitted on 26 Oct 2018

HAL is a multi-disciplinary open access archive for the deposit and dissemination of scientific research documents, whether they are published or not. The documents may come from teaching and research institutions in France or abroad, or from public or private research centers.
L'archive ouverte pluridisciplinaire HAL, est destinée au dépôt et à la diffusion de documents scientifiques de niveau recherche, publiés ou non, émanant des établissements d'enseignement et de recherche français ou étrangers, des laboratoires publics ou privés. 


\title{
Price and network dynamics in the European carbon market
}

\author{
Andreas Karpf ${ }^{\mathrm{a}, *}$, Antoine Mandel ${ }^{\mathrm{b}}$, Stefano Battiston ${ }^{\mathrm{c}}$ \\ a Centre d'Économie de la Sorbonne, University Paris 1 Pantheon-Sorbonne, France \\ ${ }^{\mathrm{b}}$ Centre d'Économie de la Sorbonne, Paris School of Economics, University Paris 1 Pantheon-Sorbonne, France \\ ${ }^{c}$ Department of Banking and Finance, University of Zurich, France
}

\section{A R T I C L E I N F O}

\section{Article history:}

Received 2 December 2016

Revised 18 May 2018

Accepted 25 June 2018

Available online 27 July 2018

\section{Keywords:}

Network

Carbon market

Climate change

Microstructure

\begin{abstract}
A B S T R A C T
This paper presents an analysis of the European Emission Trading System as a transaction network. It is shown that, given the lack of well-identified trading institutions, industrial actors had to resort to local connections and financial intermediaries to participate in the market. This gave rise to a hierarchical structure in the transaction network. It is then shown that the asymmetries in the network induced market inefficiencies (e.g., increased bid-ask spread) and informational asymmetries, that have been exploited by central agents at the expense of less central ones. Albeit the efficiency of the market has improved from the beginning of Phase II, the asymmetry persists, imposing unnecessary additional costs on agents and reducing the effectiveness of the market as a mitigation instrument.
\end{abstract}

(c) 2018 Elsevier B.V. All rights reserved.

\section{Introduction}

The European Union Emission Trading Scheme (EU-ETS) is the cornerstone of European climate policy. On the one hand, it should allow Europe to reduce its carbon emissions at the least possible cost (see e.g., Stavins, 1995). On the other hand, it should induce economic actors to account for the cost of carbon in their investment decisions (see e.g., Koch et al., 2014; Laing et al., 2013). To fulfil these objectives, the price of carbon has to be a strong and stable signal, the carbon market has to aggregate information efficiently and rapidly. The history of the ten first years of the market shows a less clearcut picture. Prices have been extremely volatile, participation has been restricted, information has been aggregated slowly and inefficiently. A characteristic failure is the fact that the massive overallocation of allowances at the beginning of phase I was diagnosed only after the first reporting period and not endogenously by the market.

We argue that the root cause of this inefficiency can easily be grasped by intuition: a poor market design that hadn't foreseen the need to organize exchange through well-identified trading institutions. Yet, we also argue that there are still lessons to be learned by looking at the mechanics of failure. A unique feature of the European carbon market is the availability of a data set which contains all the transactions performed on the market: the European Union Transaction Log (EUTL). Therefrom, the complete transaction network can be reconstructed. One can then relate the evolution of the structure of the network to the emergence of market inefficiencies.

We hence follow the growing strand of literature that investigates market dynamics with a network-based approach, to gain a detailed understanding of the structure of the EU-ETS market and the relationships between network structure, informational asymmetries and market dynamics. Therefore a set of empirical relationships between the structure of the trade network and the outcome/efficiency of the market is established. More specifically with regard to the latter, we track

\footnotetext{
* Corresponding author.

E-mail addresses: andreas.karpf@univ-paris1.fr (A. Karpf), antoine.mandel@univ-paris1.fr (A. Mandel).
} 


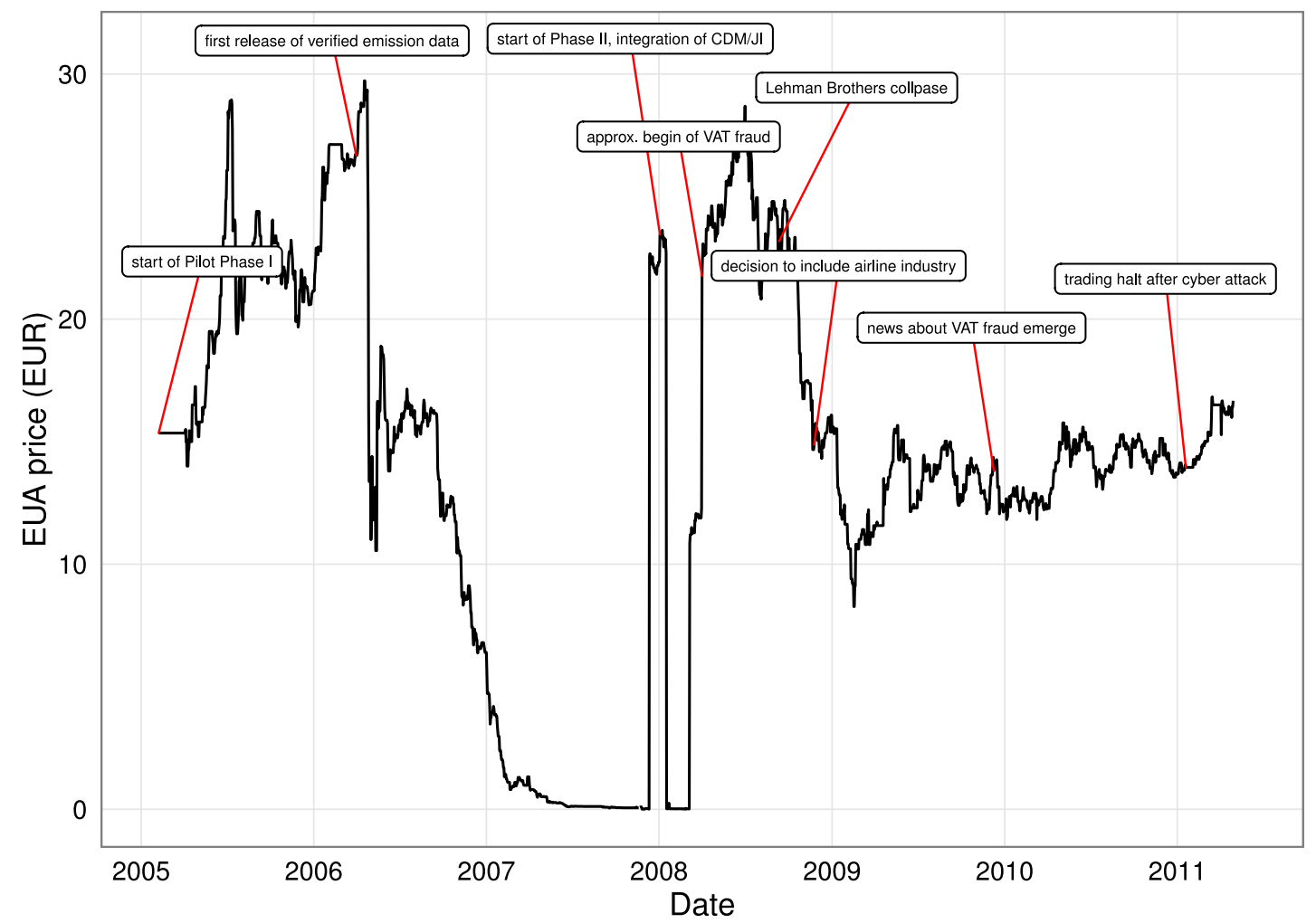

Fig. 1. The price of the EUAs over time, annotated with important market events (see similar figures in Borghesi and Montini, 2016; EEA, 2015).

the evolution of prices and bid-ask spreads. These empirical relationships can be used to track future developments in European carbon trading but also to assess the efficiency of other markets.

Our analysis shows that in the absence of a central market place, agents had to resort to local networks and financial intermediaries to exchange emission certificates. This led to the emergence of hierarchical and assortative networks with fat tailed degree distributions, which turned out to be rather inefficient in terms of the price discovery mechanism and the incorporation of new information. We further show how informed traders can be characterized in terms of centrality measures, and how the evolution of connectivity patterns can serve as an indicator for volatility or liquidity on the market. We find that market efficiency improved during Phase II as the share of spot market trading increases. It is however also shown that the major flaws of the EU ETS in principle persist.

The paper also provides a methodological contribution by introducing a Partial Least Squares Path Modeling (PLS-PM) approach to define endogenously the temporal evolution of the network rather than resorting to an exogenously fixed timewindow. Using this approach allows to investigate the structural evolution of the trading network in a dynamic manner.

The remainder of the paper is organized as follows. Section 2 reviews the related literature. Section 3 provides a description of the organization, the history and the data of the European Emission Trading System. Sections 4 and 5 provide respectively a static and a dynamic analysis of the network. Section 6 concludes.

\section{Related literature}

The EU-ETS has been the first large-scale carbon market in operation. As such, its performance has been extensively analyzed in the literature. A comprehensive overview of the design, the history and of the early literature on the EU-ETS is given in Ellerman (2010) while Ellerman et al. (2016) documents recent institutional developments. This history can also be summarized by the evolution of the carbon price illustrated in Fig. 1.

The analysis of the determinants of price formation and the management of risks related to carbon markets have been challenging issues for financial econometrics, notably because of the interactions between carbon markets, energy markets and the macro-economy. In this respect, a large body of work by Chevallier and co-authors (see Chevallier, 2011; Zhu and Chevallier, 2017, for an overview) has investigated extensively drivers and structural changes in carbon prices, the informational efficiency of EU ETS, and cross-market linkages between emissions trading and energy markets (see Alberola et al., 2008; Zhu and Chevallier, 2017; Zhu et al., 2015a; 2014; 2015b). Complementarily, a large literature in mathematical finance (see e.g., Borovkov et al., 2011; Carmona and Hinz, 2011; Chevallier and Sévi, 2014; Howison and Schwarz, 2012) has proposed formal models of the dynamics of carbon prices as stochastic processes and derived therefrom pricing methodologies for carbon derivatives. 
Overall, there is a relative consensus in the empirical literature on the fact that allowance prices are significantly related to energy prices and economic activity (see the surveys Hintermann, 2010, and Hintermann et al., 2015). However, there remains a lot of uncertainty and instability in the quantitative relationships. Creti et al. (2012) emphasize discrepancies between phase I and phase II by putting forward the presence of different cointegration relationships between the phases. They also put forward that the influence of "fundamentals" materialize more clearly in the second phase and identify a number of complementary price drivers such as policy events. Koch et al. (2014) provide similar quantitative results and additionally find that the usage of renewables has a significant explanatory power on the price.

With respect to the efficiency of the market, a recent survey (Martin et al., 2015) emphasizes three main facts about the EU-ETS: (i) it has had a robust negative impact on emissions, (ii) it didn't have strong detrimental effects on economic activity and (iii) it caused a small part of the increase in low-carbon innovation during phase 2. Yet, a number of contributions question the efficiency of the market, in particular in terms of aggregation of information. Hintermann (2010), and Hintermann et al. (2015) emphasize that new information, with regard to fundamentals like electricity prices or weather, were only incorporated with a substantial lag and that it remains unclear, even after the second phase, if the price " reflects marginal abatement costs, or whether there is a price wedge caused by transaction costs, price manipulation, or other sources of inefficiency". Palao and Pardo (2012) show the presence of price clustering in the European Carbon Futures Markets, which they interpret as a sign of inefficiency and as a weakness of the price signal provided by the market. Charles et al. (2013) investigate carbon markets with regard to cost-of-carry hypothesis, i.e., the fact that future prices can be expressed as a function of the spot price and the cost of carry. The hypothesis is rejected in all cases implying arbitrage possibilities and thus an inefficient functioning of the market. Medina et al. (2014) investigate the performance of the market from a microstructure perspective. They show that trading frictions and volatility decreased from Phase I to Phase II but that the contribution of noise to volatility increased during Phase II, resulting in lower informational quality of the price changes.

The potential sources of these inefficiencies have been investigated in a series of contributions that have tried to identify the micro-economic and behavioral patterns of participation in the market. Engels (2009) reports the results of a survey on the sources of information and expertise used by European companies to define their trading strategies on the EUETS. The answers emphasize an important lack of information exemplified by the fact that a large share of companies did not know, and/or did not attend to compute, their own abatement costs. Similar conclusions have been reached by Martin et al. (2014) on the basis of interviews with managers of a randomly selected sample of firms participating in the EU-ETS. They find that a majority of the interviewees do not participate in the market and even point out that a nonnegligible share of the population of firms has perceived the EU-ETS as a compliance mechanism rather than a market-based policy. Another series of contributions build on the EUTL dataset to provide a more quantitative perspective on participation in the market. Betz and Schmidt (2016) perform a cluster-based analysis of the transaction data to characterize different types of trading behavior: they show that the vast majority of accounts are passive and identify a small number of active traders that can be mainly partitioned between financial services and ETS regulated sectors. Jaraite et al. (2012) emphasize the role of transaction costs (e.g., information and search costs) in explaining why some firms did not participate in the European emissions trading market or chose to trade allowances indirectly via third parties. Zaklan (2013) show that size, sector, and ownership structure play a significant role in the firms' decision whether to participate in the market together with market-specific factors such as the value of the firms' free permit allocation and its relative compliance position. These converging evidences about lack of participation in the market, lack of effort in the collection of information and persistent asymmetries between participants suggest that competitive/price pressure does not truly bite on the market. It is therefore impossible to assess what is the actual constraint that the emission cap puts on industries, what the carbon price truly stands for.

Our contribution complements these findings by demonstrating how these inefficiencies and informational asymmetries can be characterized quantitatively through the structure of the transaction network. More broadly, we aim at contributing to a better understanding of the formation of markets through a quantitative analysis of this process in one of the few largescale natural experiments that has been documented. Our contribution hence relates to the burgeoning stream of literature, which emphasizes the analysis of the topological properties of transaction networks as a way to capture in a condensed manner the structural properties of markets. Such an approach has been successfully applied to a number of issues related to micro-finance (Banerjee et al., 2013), commodity markets (see Vignes and Etienne, 2011 and the contributions introduced in Sapio et al., 2011), firms' demographics (Gualdi and Mandel, 2016), international trade (Duenas and Fagiolo, 2014) or systemic risk (Battiston et al., 2012a; 2012b; Chinazzi et al., 2013; Iori et al., 2008).

\section{The European emission trading system}

\subsection{Design and dynamics of the market}

In the framework of international agreements on climate change mitigation, the European Union has committed to reduce its greenhouse gas emissions (GHG), with respect to their 1990 level, by $20 \%$ in 2020 and 40\% in 2030. Two main types of policies have been implemented in this perspective. First, a range of regulatory measures has been put in place to reduce emissions in sectors such as transport and agriculture where emissions are diffuse (henceforth referred to as non-ets 
sectors). Second, a cap-and-trade system, the European Union Emission Trading System (EU-ETS), has been put in place for the most GHG-intensive sectors in the power and manufacturing industry (the ETS sectors).

The principle of the cap-and-trade system is that the regulator fixes a global ceiling on emissions (for a given period) and creates the corresponding amount of allowances (EUAs or European Allowance Units in the context of the EU-ETS). These allowances are then allocated (e.g., on the basis of historical emissions) or auctioned, in particular to the emitters under regulation. These emitters then have to surrender each year an amount of allowance corresponding to their actual emissions, which are permanently recorded at their installations. Allowances should therefore become a scarce resource. As they are moreover legally tradable, there de facto exists a market for allowances (also referred to as the carbon market). On this market, emitters which have reduced their emissions below their quota can sell their remaining allowances, while emitters which have exceeded their quota can buy available allowances. Agents should then arbitrate between emission trading and investments in emission reduction technology, until marginal abatement costs are equalized. In theory the aggregate emissions should thereby be reduced at the least possible cost.

The European Emission Trading System (ETS) is the world's largest cap-and-trade system. As of 2017, it covers 11,000 installations representing around 50\% of the greenhouse gas (GHG) emissions in Europe (European-Commission, 2015). Each of these installations is assigned an operator holding account (OHA) that allows trading of allowances and through which allowances must be surrendered yearly to cover the installation's emissions. A fine (currently of 100 euros) is applied to the verified emissions in excess of the allowances surrendered. Beyond regulated emitters (i.e., OHAs), the market is open to other participants, notably financial intermediaries, against the payment of a fee. These entities are referred to as Person Holding Accounts (PHA). EUAs can be traded bilaterally, over the counter (OTC) via a broker or on one of Europe's climate exchange markets like the European Climate Exchange (ECX) or the European Energy Exchange AG (EEX). For the time for which the transaction data set is available the most common form of transactions was OTC.

The development of the market has been organized in phases: pilot phase I (2005-2007), phase II (2008-2012), and phase III (2013-2020). There have been major institutional changes during these different phases. First, the scope of the market has grown, geographically with the inclusion of Norway, Iceland and Liechtenstein from phase II on, and in terms of sectoral coverage with the inclusion of aviation in phase II and that of aluminum and petrochemicals in phase III. It is also the case that supply of allowances to the market has been partially extended from phase II onwards to emission reduction certificates produced under the flexibility mechanisms of the Kyoto protocol (see Ellerman et al., 2016 for details). Second, the allowances have became transferable/bankable (to future phases) from phase II onwards (whereas unused allowances at the end of phase 1 were cancelled). Third, from phase III onwards, the yearly global cap has been systematically decreased (by 1.74\%). Finally, and perhaps most importantly, the mode of allocation has shifted from almost complete free allocation (grandfathering) of allowances in phases I and II to auctioning as a default mode of allocation in phase III (but for the industries deemed at risk of carbon leakage).

Fig. 1 above summarizes the history of the early years of the market. While the price of allowances in the first year of the EU ETS was nearly constantly above twenty euros per ton, the publication of first verified emission data in April 2006 indicated a large overallocation of certificates and resulted into a market crash of close to $60 \%$. The fact that allowances were not bankable from phase 1 to phase 2 then brought prices down to a level close to zero from mid-2007 on. With the beginning of Phase II prices bounced back to pre-“compliance-break" (Alberola and Chevallier, 2009) levels in mid2008. In subsequent years the price fluctuated between ten and fifteen Euros and latter fell close to five euros. The longterm instability of the price has necessarily undermined the efficiency of the market both as a mean to equalize marginal abatement costs and as a signal to long-term investors. The EU-ETS was also heavily criticized for the windfall profits free allocation yielded, in particular to the power industry (see Sijm et al., 2006).

Part of the observed volatility can be explained by exogenous drivers such as the financial crisis or the dynamics of Global climate policy (Koch et al., 2014). Behavioral factors such as the lack of informed participation have probably also been very detrimental to the functioning of the market (see the literature review above). Changes in the institutional setting that were implemented in view of the failures observed during phase I, notably the shift from free allocation to auctioning, might also have perturbed expectations and the price formation process. This effect has possibly been amplified by the uncertainty implied by the political dimension of the issue: some of these measures, such as the exemption of auctioning for industries seen at risk of carbon-leakage, were indeed the subject of intense lobbying activity (see e.g., Gullberg, 2008; Hepburn et al., 2006). The massive VAT carousel fraud (Frunza et al., 2011) or the fishing attack of January 2011 have also been potentially important source of noise and uncertainty.

Yet, the micro-economic channels through which these exogenous shocks have impacted the market remain unclear. It is also an open question whether part of this volatility/inefficiency has emerged endogenously from the micro-economic workings of the market. Our aim in this paper is to put the focus on these more structural aspects. We investigate whether the way the market self-organized, in absence of a centralized trading platform, might have contributed to and/or can be used to characterize the inefficiency of the market and the presence of informational asymmetries.

\subsection{A data driven analysis}

To perform this structural analysis, we build on a unique feature of the EU-ETS: the availability of a public registry of transactions that allow us to reconstruct the complete network of transactions and hence to observe, "in vivo", the creation of a market. 

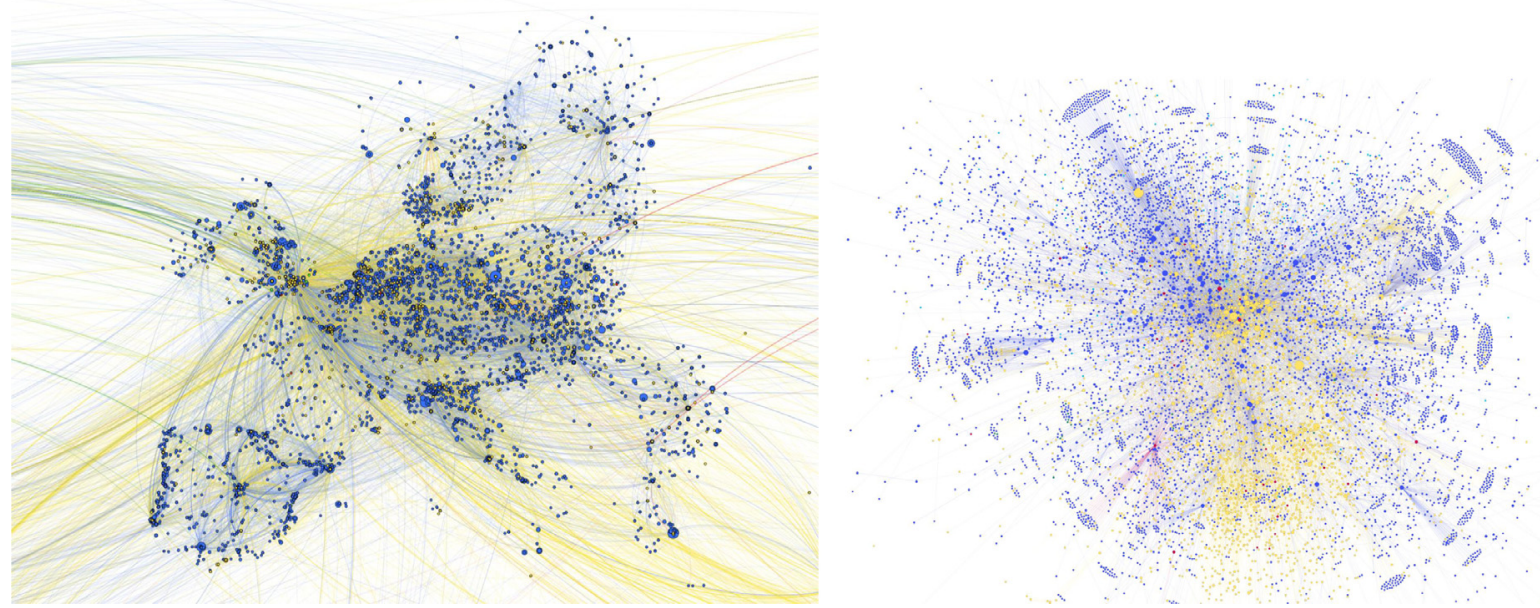

Fig. 2. The ETS network plotted with respect to the geographical position (left) and the centrality (fight) of nodes (yellow and blue indicate financial and industrial agents respectively, the edge color is the same as that of the source node). (For interpretation of the references to color in this figure legend, the reader is referred to the web version of this article.)

By law, ${ }^{1}$ every transaction in the ETS has to be recorded in a public registry maintained by the European commission, the Community Independent Transaction Log (CITL). The complete dataset is made publicly accessible with an embargo of three years. ${ }^{2}$ We have extracted the entire transaction and compliance data set from 2005 to 2011 using the Python library "scrapy". This data set comprises 520,000 transactions as well as detailed information about installations, accounts and the compliance process (allocation, surrendering, verified emissions). For our analysis, transactions connected to the administration of the ETS by governments were discarded. Namely, only transaction types 3-0, 3-21 and 10-0 were considered. This brings down the number of transactions to approximately 364,000. We added spot prices of the European Allowance Units from Bloomberg to the data set. In the cases this was possible, we also identified the global ultimate owners of firms active on the European emission via the "Ownership Links and Enhanced EUTL Dataset" (Jaraite et al., 2013) The matching between the datasets was done on the basis of the Permit IDs (unique alphanumeric code identifying the installation), installation names and PHA/OHA names. ${ }^{3}$ Using the address information contained in the account information we added geocoding to the data set (longitude, latitude) and location specific temperature information. This synthetic dataset delivers a comprehensive picture of the European emission market. Table 1 displays descriptive statistics for a selection of ETS and abatement related variables contained in the data set, by country and agent type. The type "Industry" refers to Operator Holding Accounts (OHA), who, in contrast to Person Holding Accounts (PHA), have the legal obligation to participate in the ETS because they operate in one of the industrial sectors covered by the respective regulations. For the period under consideration in the paper (2005-2011), the PHAs active in the market can mainly be attributed to banks and brokers. ${ }^{4}$ Their categorization was achieved by applying regular expressions to the company names of PHAs. We refer to this sub-group as "Finance". There is also a small number of PHAs which cannot be attributed to financial agents. This sub-group is negligible in numbers, referred to further on as "other" and for space reasons this group is not displayed in summary table. The data shown in Table 1 comprises allowances attributed to OHAs in tons of $\mathrm{CO} 2$, the emissions measured at OHA installations in tons of $\mathrm{CO} 2$, the volume of EUAs traded in thousand tons of $\mathrm{CO} 2$ and the number of companies by type. It has to be noted that these descriptive statistics refer only to agents who were active in the emission market between 2005 and 2011.

\section{The static trading network}

In the remainder of the paper we adopt a network perspective on the European emission market, in which transactions are regarded as directed edges between a seller (source vertex) and a buyer (target vertex). We first adopt a static perspective where the network is formed by the set of all transactions independently of their time stamp. Fig. 2 provides a graphical representation of this aggregate network and underlines the presence of different groups of agents in the network. Industrial actors are the largest group (6384 actors). They correspond to "operator holding accounts", that is companies which form the primary demand and supply of allowances as they have a legal obligation to surrender allowances. The second largest group

\footnotetext{
${ }^{1}$ Directives 2003/87/EC and 2009/29/EC.

2 See http://ec.europa.eu/environment/ets/.

3 The "Ownership Links and Enhanced EUTL Dataset" only covers the trading periods from 2005 to 2007. Therefore, we have only used this consolidated data for the graphical depiction of the network in Fig. 2.

${ }^{4}$ The switch over to the Union registry of transactions in mid-2012 partially modified the identification codes and introduced an updated version of the account types. Thus our classification might have to be updated if it were to be used for latter periods.
} 
Table 1

Descriptive statistics of a selection of ETS and abatement variables by type and country 2005-2011 (Allowances attributed to OHAs in tons of CO2; emissions measured at OHA installations in tons of CO2; the volume of EUAs traded in thousands; the number of companies by type).

\begin{tabular}{|c|c|c|c|c|c|c|c|c|}
\hline \multirow[t]{2}{*}{ Country } & \multicolumn{2}{|c|}{ Allowances t/CO2 } & \multicolumn{2}{|c|}{ Emissions t/CO2 } & \multicolumn{2}{|c|}{ Volume (in thousands) } & \multicolumn{2}{|c|}{ Companies } \\
\hline & Finance & Industry & Finance & Industry & Finance & Industry & Finance & Industry \\
\hline All & 0 & $8.997 e+09$ & 0 & $1.889 \mathrm{e}+10$ & $3.379 e+10$ & $1.364 \mathrm{e}+10$ & 2522 & 6559 \\
\hline AT & 0 & $1.273 e+08$ & 0 & $2.564 \mathrm{e}+08$ & $1.237 \mathrm{e}+08$ & $2.071 \mathrm{e}+08$ & 28 & 128 \\
\hline $\mathrm{Be}$ & 0 & $2.461 \mathrm{e}+08$ & 0 & $4.754 \mathrm{e}+08$ & $5.949 \mathrm{e}+08$ & $3.151 \mathrm{e}+08$ & 27 & 154 \\
\hline BG & 0 & $2.370 \mathrm{e}+07$ & 0 & $6.225 e+07$ & $7.556 e+06$ & $2.814 \mathrm{e}+07$ & 17 & 71 \\
\hline $\mathrm{CZ}$ & 0 & $3.890 \mathrm{e}+08$ & 0 & $6.932 \mathrm{e}+08$ & $2.586 e+08$ & $3.556 \mathrm{e}+08$ & 64 & 274 \\
\hline De & 0 & $2.293 e+09$ & 0 & $4.926 \mathrm{e}+09$ & $3.350 \mathrm{e}+09$ & $3.049 e+09$ & 197 & 1005 \\
\hline DK & 0 & $6.849 e+07$ & 0 & $1.367 e+08$ & $4.721 \mathrm{e}+09$ & $9.891 e+08$ & 516 & 260 \\
\hline ee & 0 & $6.535 e+07$ & 0 & $1.261 \mathrm{e}+08$ & $3.934 \mathrm{e}+07$ & $2.727 e+07$ & 18 & 26 \\
\hline eS & 0 & $7.574 \mathrm{e}+08$ & 0 & $1.649 \mathrm{e}+09$ & $5.308 \mathrm{e}+08$ & $7.855 e+08$ & 52 & 810 \\
\hline FI & 0 & $2.054 \mathrm{e}+08$ & 0 & $3.818 \mathrm{e}+08$ & $5.515 e+07$ & $2.331 \mathrm{e}+08$ & 24 & 176 \\
\hline FR & 0 & $4.879 e+08$ & 0 & $8.450 e+08$ & $1.178 \mathrm{e}+10$ & $1.374 \mathrm{e}+09$ & 281 & 509 \\
\hline GB & 0 & $1.090 \mathrm{e}+09$ & 0 & $2.628 \mathrm{e}+09$ & $8.366 \mathrm{e}+09$ & $3.396 e+09$ & 309 & 561 \\
\hline GR & 0 & $3.016 e+08$ & 0 & $6.907 e+08$ & $1.256 \mathrm{e}+07$ & $4.220 \mathrm{e}+07$ & 21 & 102 \\
\hline $\mathrm{HU}$ & 0 & $1.064 \mathrm{e}+08$ & 0 & $2.202 \mathrm{e}+08$ & $5.015 e+07$ & $4.821 \mathrm{e}+07$ & 18 & 148 \\
\hline Ie & 0 & $1.001 \mathrm{e}+08$ & 0 & $2.090 e+08$ & $8.048 \mathrm{e}+07$ & $5.148 \mathrm{e}+07$ & 13 & 67 \\
\hline IT & 0 & $8.881 e+08$ & 0 & $2.008 \mathrm{e}+09$ & $7.276 e+08$ & $8.096 e+08$ & 132 & 583 \\
\hline LI & 0 & $8.246 e+03$ & 0 & $1.896 \mathrm{e}+04$ & $2.306 \mathrm{e}+08$ & $1.550 \mathrm{e}+04$ & 83 & 1 \\
\hline LT & 0 & $2.577 e+07$ & 0 & $4.153 e+07$ & $9.823 e+06$ & $4.406 e+07$ & 8 & 69 \\
\hline LU & 0 & $3.955 e+06$ & 0 & $5.240 \mathrm{e}+06$ & $1.024 \mathrm{e}+07$ & $3.850 \mathrm{e}+06$ & 7 & 13 \\
\hline LV & 0 & $1.279 \mathrm{e}+07$ & 0 & $1.790 \mathrm{e}+07$ & $7.649 e+07$ & $8.598 e+06$ & 7 & 73 \\
\hline NL & 0 & $3.960 \mathrm{e}+08$ & 0 & $7.206 \mathrm{e}+08$ & $1.103 e+09$ & $1.133 e+09$ & 129 & 234 \\
\hline other & 0 & $2.168 \mathrm{e}+07$ & 0 & $1.029 \mathrm{e}+08$ & $9.748 \mathrm{e}+08$ & $4.533 e+07$ & 326 & 63 \\
\hline PL & 0 & $8.184 e+08$ & 0 & $1.723 e+09$ & $2.900 \mathrm{e}+08$ & $2.602 \mathrm{e}+08$ & 94 & 420 \\
\hline PT & 0 & $1.381 \mathrm{e}+08$ & 0 & $2.679 \mathrm{e}+08$ & $6.885 e+07$ & $1.401 \mathrm{e}+08$ & 8 & 201 \\
\hline RO & 0 & $2.056 \mathrm{e}+08$ & 0 & $3.151 e+08$ & $1.088 \mathrm{e}+08$ & $1.287 e+08$ & 37 & 159 \\
\hline Se & 0 & $1.013 e+08$ & 0 & $1.853 e+08$ & $1.271 \mathrm{e}+08$ & $7.084 \mathrm{e}+07$ & 65 & 229 \\
\hline SI & 0 & $2.850 \mathrm{e}+07$ & 0 & $6.872 \mathrm{e}+07$ & $5.557 e+06$ & $1.410 \mathrm{e}+07$ & 10 & 79 \\
\hline SK & 0 & $9.561 \mathrm{e}+07$ & 0 & $1.377 e+08$ & $9.101 \mathrm{e}+07$ & $8.359 e+07$ & 31 & 144 \\
\hline
\end{tabular}

(2688 agents) consists in financial actors, which enter the market as brokers or for financial engineering considerations. The third biggest group (106 agents) are agents which participate in the European emission market in the context of the Clean Development Mechanism (CDM). Two smaller groups are governmental organizations (40) as well as foundations/activists $(24)^{5}$ The core purpose of the latter group is the reduction of greenhouse gas emissions. Some, not all, try to increase the price of EUAs by buying and discarding certificates.

\subsection{The determinants of network formation}

The complex structure of the ETS network is the outcome of a large number of micro-level interactions. Accordingly, in view of explaining the aggregate properties of the market, we first investigate the determinants of individual transactions.

\subsubsection{Exogenous drivers}

We first focus on the exogenous drivers of link formation. In this respect, Fig. 3 displays the flows of transactions between type and country groups. It indicates there is a tendency for agents to trade with peers from the same country and from different types. In other words, the network seems to display strong assortativity with regards to the location of agents and dissortativity with regards to their type.

In order to confirm these insights quantitatively, we ran an Exponential Random Graph model (ERGM) on the EU ETS trading network. ${ }^{6}$ We run the ERGM on the unweighted network as our main focus is the influence of homophily/heterophily in link formation on the topology of the network. Using the weighted network would put a stronger focus on the volume of transactions and might have exacerbated bias in the estimation related to the fact the number of accounts from different groups and countries is unbalanced. Table 2 displays the results of our analysis. ${ }^{7}$. It confirms that agents have a propensity to trade with peers from the same country (strictly positive and significant coefficient of the term

\footnotetext{
5 As mentioned above, in our analysis only transactions deemed to be relevant for the price formation were considered. Transactions connected to the administration (attribution of emission certificates, surrendering etc.) of the market were discarded. Governmental organizations thus appear here as normal market participants, who buy and sell certificates. There role is thus not as dominant as one could expect otherwise. Their presence in the analysis is not altering the results.

${ }^{6}$ We used the ergm package of the R statnet library (Handcock et al., 2003).

7 The edges term can be regarded as a intercept or offset which controls for the degree of connectedness (density) in the network. The transitive term can be seen as an auxiliary term to guarantee robustness of the mixing parameters which are in the center of our interest. For the estimation a Maximum Pseudo Likelihood algorithm was used.
} 

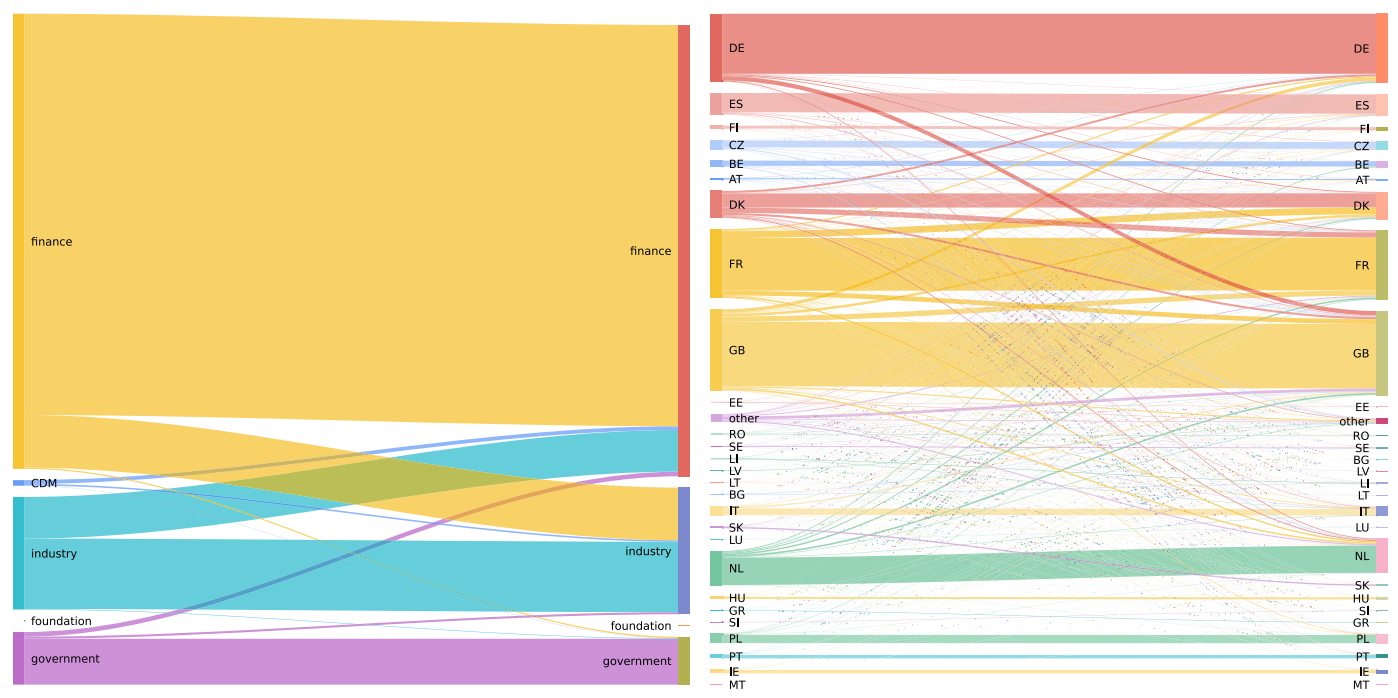

Fig. 3. Transaction flows between different groups.

Table 2

Results of the ERG model estimated on the EU ETS network.

\begin{tabular}{ll}
\hline & EU ETS trading network \\
\hline Edges & $-8.784^{* * *}$ \\
& $(0.033)$ \\
Transitive & $0.376^{* * *}$ \\
& $(0.002)$ \\
Nodematch.country & $2.813^{* * *}$ \\
& $(0.012)$ \\
Mix.type.finance.finance & $0.944^{* * *}$ \\
& $(0.034)$ \\
Mix.type.industry.finance & $0.226^{* * *}$ \\
& $(0.034)$ \\
Mix.type.finance.industry & $0.287^{* * *}$ \\
& $(0.034)$ \\
Mix.type.industry.industry & $-0.998^{* * *}$ \\
& $(0.034)$ \\
Akaike Inf. Crit. & $457,197.300$ \\
Bayesian Inf. Crit. & $457,311.100$ \\
\hline
\end{tabular}

Notes: ${ }^{* * *}$ Significant at the $1 \%$ level. ${ }^{*}$ Significant at the $5 \%$ level. ${ }^{*}$ Significant at the $10 \%$ level.

nodematch.country). With respect to the mixing behavior among groups, the results clarify the importance of financial agents. They attract transactions from their industrial peers (the coefficients of the terms mix.type.industry.finance and mix.type.finance.industry are both positive and significant) and also strongly interact among themselves (homophily measured by coefficient mix.type.finance.finance). Oppositely, industrial agents exhibit a strong propensity to trade with partners of different type (heterophily).

These results confirm that, lacking a central market place, industrial agents resort to local networks and brokerage services from the financial industry in order to trade allowances. The slightly stronger effect observed for transaction from type finance to industry also suggests that brokerage services are more intensively used by buyers than by sellers.

\subsubsection{Endogenous drivers}

The choice of trading partners does not only depend on exogenous factors. The importance of the position of an agent in the market might also be fundamental in attracting transactions. A network-based perspective allows to quantify these aspects by relating the formation of links to the existing structure of the network.

The degree is the most basic measure of importance of a node in a network. From a structural perspective, assortativity then measures the propensity of nodes to connect to similar nodes in terms of degree. In order to analyze the assortativity of the ETS, we use the Maslov-Sneppen algorithm (see Maslov and Sneppen, 2002), which compares the empirical network to a null-model generated by a rewiring procedure (see Appendix A for details). In the context of the ETS, this null model can be seen as representing the structure that would have expectedly emerged if all transactions had been performed through the veil of a centralized exchange platform. The results of the analysis are presented in Fig. 4 through degree-degree correlation 

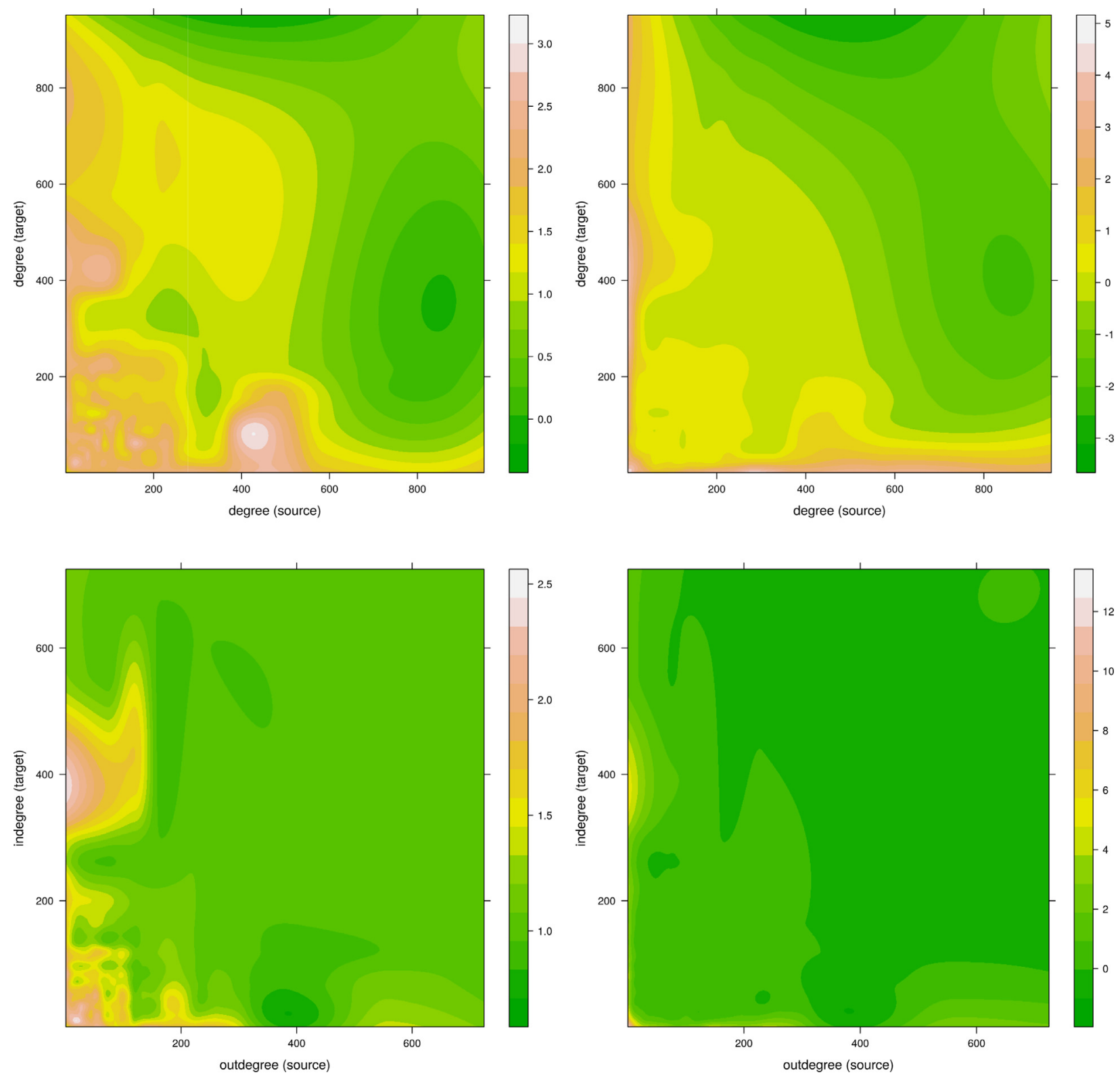

Fig. 4. Degree-degree correlation profiles generated by the Maslov-Sneppen algorithm for the ETS as an undirected (left) and directed (right) graph.

profiles. They show on the one hand a slightly increased connectedness within the group of highly connected nodes (the lighter green area in the upper right corner of the left hand-side plot) and on the other hand significantly increased degree of asymmetric connectedness i.e., between low- and high degree nodes (the yellow to red area along the axes). These results suggest that large, and hence visible, actors attracted more transactions than they would have through a centralized market.

\subsection{Degree distribution and structure of the trading network}

The network structure that emerges from micro-level interactions can be analyzed via its degree distribution. In Fig. 5 the degree distribution of the network is displayed on a log-log-scale. The graph clearly shows that the distribution exhibit fat tails. Translated into our market context this means, that there are agents whose degree strongly exceeds the average. These agents, which are much better connected than the average, are likely to play a central role in the functioning of the market and hence acquire private information on its operation.

To characterize the hierarchical structure of the trading network, we follow Li and Schürhoff (2014) and investigate the relations between degree and clustering coefficient (see Fig. 6). We find a negative relationship between the connectedness 


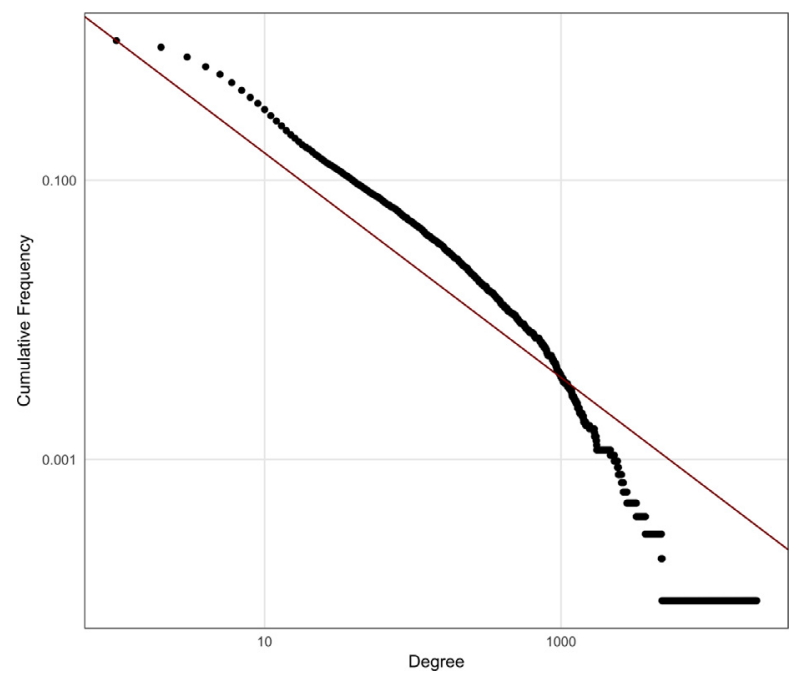

Fig. 5. Degree distributions.
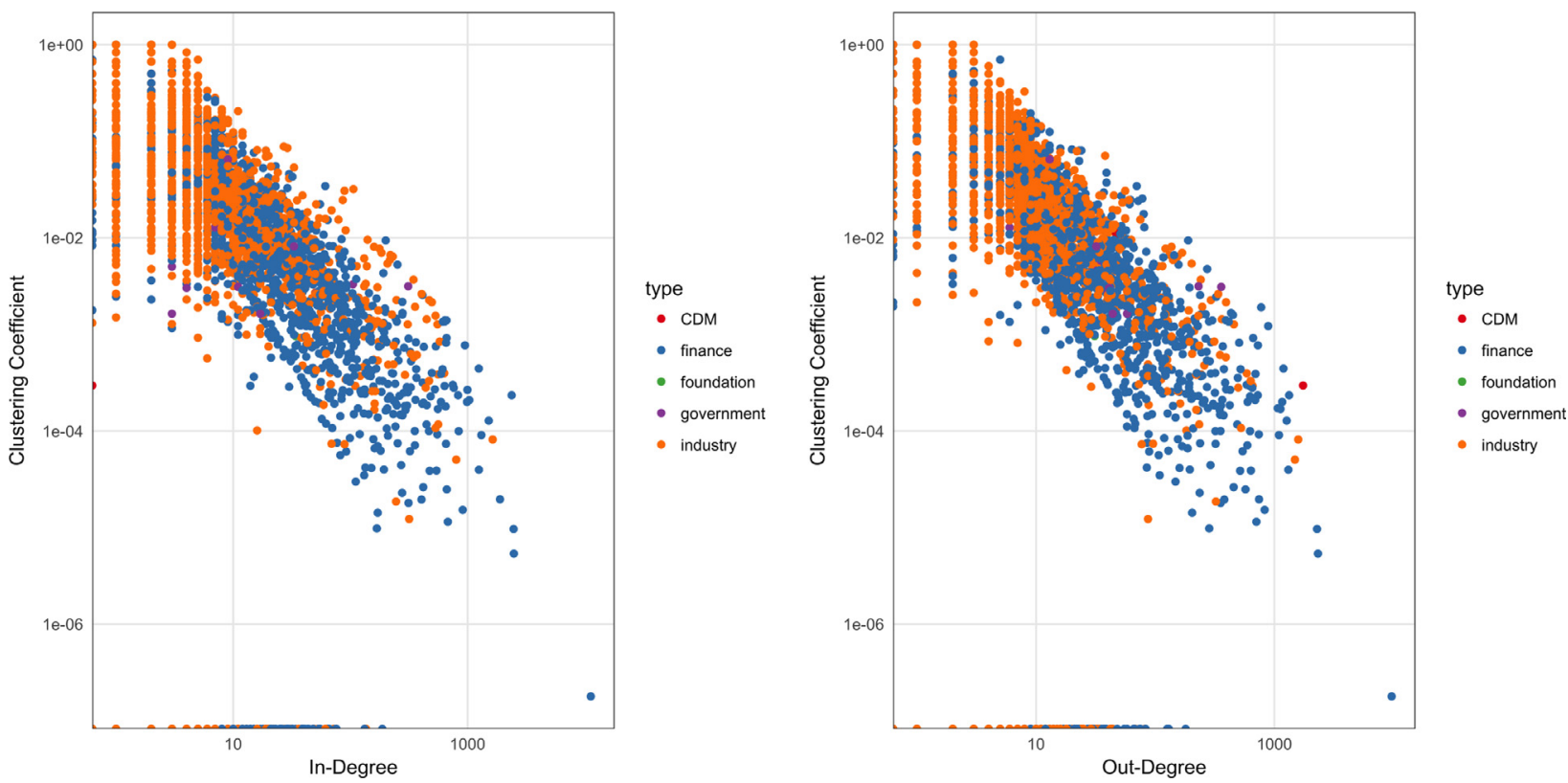

Fig. 6. Degree vs. clustering.

of agents (in- and out-degree) and their clustering behavior. According to Li and Schürhoff (2014), this negative relationship suggests that "sparsely connected dealers are part of local markets and order flow between the different local markets are being maintained by a few central hubs". This hierarchical structure is clearly highlighted in Fig. 2, which shows that the trade network is characterized by a core of strongly connected agents from the finance industry (yellow nodes), surrounded by looser connected agents from the industry in the periphery of the graph. This structural asymmetry might be a reflection of the informational asymmetry on the ETS market which authors as (Medina et al., 2014) have emphasized.

Overall, our analysis suggests that, in absence of well identified trading institutions, the formation of the EU-ETS trading network was driven by the need for traders to identify a potential counterpart through geographical proximity or prominence in the network. These constraints led to the formation of a complex trade network characterized by disassortative mixing behavior, a fat tailed degree distribution and a hierarchical structure, with highly connected financial agents in the core and lesser connected industrial agents clustering around this core. In this setting, large central agents have likely gained private information about the functioning of the market and possibly used it to extract informational rents while distorting the price formation process. To test this hypothesis, we perform in the following section an analysis of the joint evolution of the network structure and market outcomes (price and bid-ask spread). 


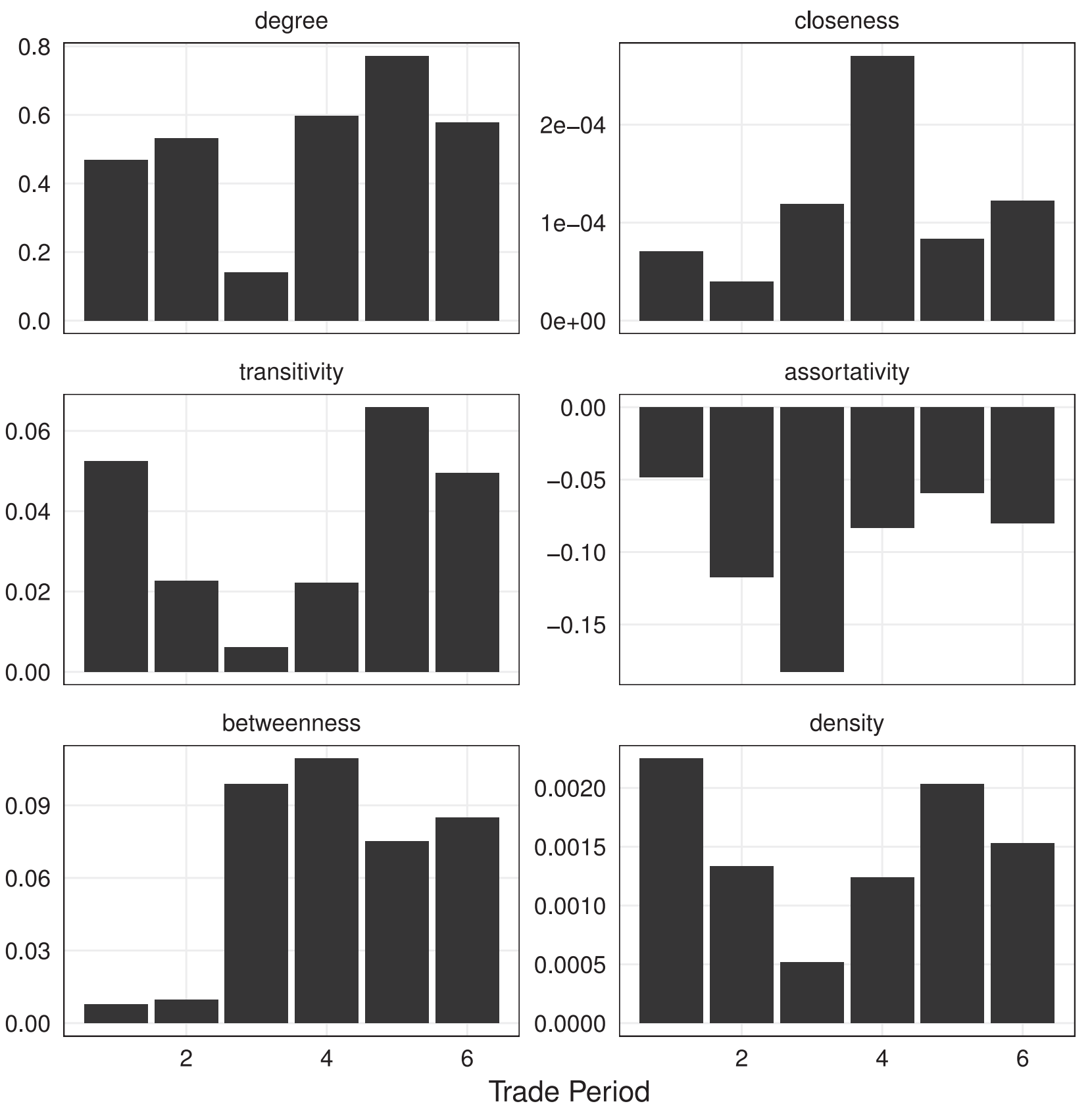

Fig. 7. Evolution of different network metrics by trade period.

\section{The dynamic trading network}

\subsection{Overview}

An outline of the dynamics of the ETS transaction network is provided in Fig. 7, which gives the evolution of key network statistics over the six first years of operation of the ETS market. ${ }^{8}$ The picture that emerges is that of a market whose activity and efficiency slowly increases over time.

The evolution of the network's degree and density underlines the fact that the intensity of trading in the EU ETS grew over time, with a peak in trade period 5 . The sustained high level of betweenness centrality from period two on indicates

\footnotetext{
${ }^{8}$ Definitions of key network measures are recalled in the appendix.
} 
Table 3

Average correlations between centrality measures and network metrics.

\begin{tabular}{|c|c|c|c|c|c|c|c|}
\hline & Degree & Pagerank & Katz & Betweenness & Density & Closeness & Clustering \\
\hline Degree & 1 & 0.840 & 0.240 & 0.660 & 0.440 & 0.180 & -0.070 \\
\hline Pagerank & 0.840 & 1 & 0.320 & 0.430 & 0.540 & -0.020 & -0.080 \\
\hline Katz & 0.240 & 0.320 & 1 & -0.100 & 0.410 & -0.270 & -0.050 \\
\hline Betweenness & 0.660 & 0.430 & -0.100 & 1 & 0.060 & 0.380 & -0.060 \\
\hline Density & 0.440 & 0.540 & 0.410 & 0.060 & 1 & -0.110 & -0.020 \\
\hline Closeness & 0.180 & -0.020 & -0.270 & 0.380 & -0.110 & 1 & 0.130 \\
\hline Clustering & -0.070 & -0.080 & -0.050 & -0.060 & -0.020 & 0.130 & 1 \\
\hline
\end{tabular}

that the network has better transmission properties, i.e trading in the market is less subject to frictions. The closeness centrality score, reflecting the average distance of one node to any node, which reached a peak in trade period four in order to fall again in successive periods tells a similar story. Degree assortativity and disassortativity describe the preferential attachment of nodes to nodes with similar connectivity and vice versa. ${ }^{9}$ While the assortativity was steadily decreasing up to trade period three, the first period of compliance Phase II, it tends towards zero in subsequent periods. This implies that agents in the later periods (Phase II) were less biased in choosing their trading partner and relied to a higher degree on market signals. This might be due to a higher degree of spot market trading in the later trading periods. While trading on spot markets only accounted to $40 \%$ in 2005 , this share rose to $70 \%$ in 2007 (Convery et al., 2008).

\subsection{The PLS-PM approach}

In the following, we aim to further refine our analysis by linking the dynamics of the network to those of key market indicators such as the EUA price and the bid-ask spread. In this perspective, a natural approach is to use time-series of market variables and network-statistics to regress the former on the latter. Therefore, we build on the state-of-the-art model for the estimation of the carbon price developed by Chevallier and co-authors (see in particular Alberola et al., 2008; Chevallier, 2011, and references above). Our strategy is to add to the standard specification of Alberola et al. (2008), variables characterizing the evolution of the structure of the network and the network centrality of actors participating in the market. In particular, we aim to investigate whether central agents can use their informational advantage to obtain better trading conditions, e.g., if other things being equal central buyers sale at a higher price when facing sellers with low centrality. The inclusion of network related variables in the regression however raises two issues.

First, as highlighted in Table 3, different centrality measures can be highly correlated. Therefore, we choose to only include degree as a measure of centrality in our model. Indeed, degree is both the simplest measure of centrality and is highly correlated with other measures (as already observed in other settings, see Valente et al., 2008). The only other network variable we include is density, which can be seen as a proxy of the trading intensity during the period.

The second issue related to the inclusion of network variables concerns the modeler's assumption about the length of time during which a trading link shall be considered active. Indeed, this assumption can strongly influence the perceived network structure. A standard approach in the literature (see e.g., Kossinets and Watts, 2006; Li and Schürhoff, 2014; Panzarasa et al., 2009; Puliga et al., 2014) is to use a sliding window on the basis of an assumption about the lifespan of a connection. The choice of the lifespan can be guided by theory or by the problem at hand. In the context of the EU-ETS, we lack such a natural assumption about the lifespan of connections. Network characteristics exhibit a sizeable variability as the window-size changes. In order to overcome this problem and to capture as much as possible of the information provided by the network-structure at different time-scales, we use a nested approach via Partial Least Square Path modeling (PLS-PM).

The Partial Least Square Path modeling method consists in combining (i) an inner model in which one seeks to explain dependent variables by latent variables and other explanatory variables and (ii) an outer model in which latent variables are constructed by taking a convex combination of variables contained in the respective equation in such a way that the explained variance of the dependent variables is maximized. In our context, the latent variable is a synthetic network characteristic (degree or density), which is constructed by taking combination of the given network statistic (degree or density respectively) measured using different window-sizes.

We apply this approach to the estimation of two inner equations for the EUA price and the bid-ask spread (the respective dependent variables are estimated simultaneously). More precisely, the model consists of:

- Two reflective latent variable equations of the form $X_{j k}=\lambda_{0 j k}+\lambda_{j k} L V_{j}+$ error $_{j k}$ with the following parameters ${ }^{10}$ :

- Degree

- Density

- 53 formative latent variable equations of the form $L V_{j}=\lambda_{0 j}+\lambda_{j k} X_{j k}+$ error ${ }_{j}$ (measurement models) with the following parameters:

\footnotetext{
${ }^{9}$ At a value of 1 the network exhibits perfect assortative mixing, while a value of -1 implies perfect disassortative mixing. Zero indicates that network is non-assortative.

${ }^{10}$ For a technical description of the different network statistics the reader is referred to Appendix B.
} 
- UK Natural Gas Futures, EUR/therm (ngase)

- Rotterdam Coal Futures, EUR/ton (coale)

- Brent Crude Futures, EUR/barrel (brente)

- UK Electricity futures, EUR/MWh (elece)

- Emissions as recorded in the EU ETS compliance database; ton CO2 (Emissions)

- Allowances attributed to OHAs, ton CO2 (Allowances)

- Volume traded, ton CO2 (Volume)

- Clean Dark spread, EUR/MWh (computed with elece and coale)

- Clean Spark spread, EUR/MWh (computed with elece and ngase)

- country specific average temperatures, $.1^{\circ} \mathrm{C}$ (avgtemp)

- Dummy variable for extraordinary ETS search events (news)

- group - (4) Dummy variables for phases identified by breakpoint test (Breakpoint)

- group - (5) Dummy variables for trade periods (Tradeperiod)

- group - (26) Country Dummy variables (Country + ISO 3166-1 alpha-2 country code)

- group - (3) Dummy variables for extreme temperature events (Tempext5, Tempext95) computed from avgtemp

- group - (2) Dummy variables indicating the group (Finance, Industry)

which, via scores of the form $L \hat{V}_{j}=\sum_{k} w_{j k} X_{j k}$ represent the embedded manifest variables.

- Two inner model equations (structural equations), explaining respectively the:

- EUA market price

- bid-ask spread

\subsection{Specification}

\subsubsection{Network statistics}

The two reflective latent variables Degree and Density are the two network metrics which are included in our model. The values of these variables measured at different window sizes are weighted as described above in their respective latent variable blocks and enter the inner model equation via the so computed latent variable scores. We decided to include these two network metrics for theoretical and technical considerations: (1) Degree centrality reflects the connectedness of an agent. Density measures the ratio between the number of active and theoretically possible connections in the network. The former thus supplies an individual level measure of centrality in the emission trading network. A better connected agent might be better informed and might thus have advantages over lesser connected and informed counterparts. Accordingly, the Degree variable enters our model as the difference between the degrees of the transferring and the acquiring agent for each transaction. The Density variable can in our context be understood as indicator for trade activity on the one hand and market transparency on the other hand; if agents had to rely to a lesser degree on better informed intermediaries (brokers) we would expect to observe a higher density. (2) It is well known that network variables are often strongly correlated with each other. Table 3 also shows this for our network data set. The correlation between Degree and Density measures is however relatively low.

The 53 formative latent variables can be understood as parameters entering the inner model equation directly. Each formative variable block only contains one variable weighted with 1 . These parameters control for other effects which might influence the price and the spread on the emission market. In the specification we follow to a large extent (Alberola et al., 2008) and the more detailed outline of these parameter by Chevallier (2011). The parameters can be grouped as follows:

\subsubsection{Energy prices}

Emissions captured by the ETS originate to a large extent in the electricity production sector, which in some parts of Europe still heavily relies on coal and gas power plants. Since the introduction of the ETS, electricity producers in Europe not only have to take into account the market prices for the respective fuels powering their plants, but also the costs of emissions thereby produced. "Fuel switching" has become a popular term in the literature describing the switching of electricity producers from coal to natural gas by technical upgrades to their plants. To capture this mechanism we included one month ahead future prices of natural gas (UK Natural Gas Futures; ngase; GBP/therm), coal (Rotterdam Coal Futures; coale; USD/tonne) and electricity (UK Electricity futures; elece; GBP/MWh of electricity per hour per day) into our model. For the rest of the economy what links emissions to economic activity are oil/fuel prices. We thus also include one month ahead future prices of Brent crude oil (Brent Crude Futures; brente; USD/barrel). All variables were converted to Euro by the respective daily rates. Like Alberola et al. (2008) we transform all energy variables with a slight variation of the one-step ahead forecast error method proposed by Helfand et al. (2006): In contrast to Helfand et al. (2006), who only uses trend and monthly dummy variables, we are additionally including yearly dummy variables. This is reasonable since we are analyzing a relatively large time frame, in which the variables naturally exhibit a much larger volatility.

\subsubsection{Abatement}

As discussed above, abatement evolves to a large degree around the question of fuel switching by electricity producers. To capture these underlying effects fully we follow Alberola et al. (2008) in including the Clean Dark as well as the Clean Spark spread in our model. The Clean Dark Spread (cldark; EUR/MWh) is the difference between the price of electricity (elece) and 
price of coal (coale) necessary to produce that electricity, corrected for the $\mathrm{CO} 2$ emissions factor of a conventional coal power plant and the current market price of CO2 in the ETS. The Clean Spark Spread (clspark; EUR/MWh) is the difference between the price of electricity (elece) and price of natural gas (ngase) necessary to produce that electricity, corrected for the CO2 emissions factor of a conventional gas power plant and the current market price of $\mathrm{CO} 2$ in the ETS. For these computations the concerned energy prices had to be converted to EUR/MWh. Alberola et al. (2008) also included the Switching Price (the shadow price at which it would make sense for electricity producers to switch from coal to gas) in their model. As we encountered multicollinearity issues when including all three variables, we decided to only incorporate the Clean Dark Spread and the Clean Spark Spread. ${ }^{11}$ Additionally to these variables derived from energy prices, we also include the number of attributed Allowances to OHAs and the number of Emissions at OHA installations.

\subsubsection{Weather}

To capture the influence of weather on the activity of electricity producers and the economy as a whole we used 8Gb of daily average, maximum and minimum temperatures from the European Climate Assessment Dataset to generate country specific temperature variables along the example of Alberola et al. (2008): We include average daily temperatures (avgtemp) and dummy variables for periods of extreme cold (Tempext5) and extreme warm (Tempext95) periods in the respective countries. A day falls into the category of hot/cold days if the temperature was five consecutive days in the highest/lowest quintile of the distribution of temperatures measured on these respective days.

\subsubsection{News effects}

The ETS was, as discussed in the beginning of this paper, in the first years characterized by scandals and irregularities. Chevallier (2011) discusses the possibility of including a dummy variable capturing the effect of institutional news on EUA prices. Unfortunately we were not able to recreate such a data set. Instead, as a proxy, we are using Google Search Trend data for a couple of keywords related to the ETS. This data normally reflects very well the concurrent media coverage of a topic. The binary variable (news) thus indicates days of high media coverage, if the number of searches is in the highest decile of the distribution of observed daily search numbers since 2004.

\subsubsection{Volume of transferred EUAs}

The numerical variable Volume represents the number of EUAs transferred between two agents on a specific day.

\subsubsection{Breakpoints}

Along Alberola et al. (2008) we are applying a breakpoint test (Zeileis et al., 2003) to the EUA price time series. We identify four breakpoints or five phases respectively. Dummy variables (break1-break4) indicating four of these five phases were included in the model.

\subsubsection{Dummy variables for type, country and trade period}

We further included dummy variables indicating the type (Finance, Industry, other was excluded), the country (Country + ISO 3166-1 alpha-2 country code) in which the account is registered and the trade period in which the respective transactions were conducted (Tradeperiod6 was left out).

\subsection{Results of the PLS-PM procedure}

The inner model exhibits a relatively good goodness of fit of 0.6775 . The results of the estimation are reported in Table 4 . As far as the interpretation of network statistics is concerned, they shall be seen as reflecting the influence on the price and the bid-ask spread of the relative network positions of sellers and buyers encountering each other on the market on a certain day. It has also to be kept in mind, that, while network metrics can be computed on a daily and individual basis, Density, Price and Bid-Ask spread are only available at the aggregate daily level. Beyond these caveats, the results support our assumption that network centrality acts has a measure of informational advantage and has a significative impact on both the price and the bid-ask spread.

\subsubsection{Price}

As far as the inner model regression for prices is concerned, we observe that the degree coefficient is positive while the density coefficient is negative. As outlined above, the Degree centrality measure included in our model, represents the difference in the degree between sellers and buyers. Hence, the positive coefficient implies that the presence of central agents drive up prices. This suggests that central agents can exploit their informational advantages to extract a profit from less central, less informed, buyers. A similar interpretation is given by Firgo et al. (2015) in the context of the Austrian retail gasoline market network. Density can be interpreted as a proxy for overall trading activity and market transparency. The negative coefficient of this variable hence implies that in our context higher trading intensity with many different partners implying a higher transparency of the market lowers EUA prices. Both coefficients for Degree and Density are highly significant.

\footnotetext{
${ }^{11}$ For technicalities of the computation of the Clean Dark Spread, Clean Spark Spread and the Switch Price the reader is referred to CDC Climate Research (2013).
} 
Table 4

Parameter estimates for the two inner model equations, with the EUA prices and the bid-ask spread as the respective dependent variables. The independent variables are the result of the two reflective latent variable equations (degree and density) and 53 formative latent variables equations (see description in Section 5.2). The parameter estimates in this context are interpreted in a similar manner as in an OLS estimation.

\begin{tabular}{|c|c|c|c|c|c|c|c|c|}
\hline & \multicolumn{4}{|l|}{ Price } & \multicolumn{4}{|l|}{ Spread } \\
\hline & Estimate & Std. Error & $t$ value & $\operatorname{Pr}(>|t|)$ & Estimate & Std. Error & $t$ value & $\operatorname{Pr}(>|t|)$ \\
\hline Allowances & -0.008 & 0.003 & -2.960 & 0.003 & -0.000 & 0.005 & -0.058 & 0.954 \\
\hline avgtemp & -0.010 & 0.002 & -5.561 & 0.000 & -0.006 & 0.004 & -1.541 & 0.123 \\
\hline break1 & -0.463 & 0.021 & -22.587 & 0.000 & -0.920 & 0.042 & -22.139 & 0.000 \\
\hline break2 & -0.916 & 0.020 & -44.816 & 0.000 & -0.897 & 0.041 & -21.671 & 0.000 \\
\hline break3 & -0.550 & 0.033 & -16.705 & 0.000 & -0.004 & 0.067 & -0.065 & 0.948 \\
\hline break4 & -0.866 & 0.036 & -23.878 & 0.000 & -0.037 & 0.073 & -0.505 & 0.613 \\
\hline brente & -0.136 & 0.002 & -88.779 & 0.000 & -0.053 & 0.003 & -17.159 & 0.000 \\
\hline cldark & -0.961 & 0.005 & -197.125 & 0.000 & -0.553 & 0.010 & -56.021 & 0.000 \\
\hline clspark & -0.181 & 0.005 & -39.363 & 0.000 & -0.341 & 0.009 & -36.696 & 0.000 \\
\hline coale & -0.289 & 0.002 & -188.086 & 0.000 & -0.156 & 0.003 & -50.209 & 0.000 \\
\hline CountryAT & -0.001 & 0.002 & -0.895 & 0.371 & -0.022 & 0.003 & -6.787 & 0.000 \\
\hline CountryBE & -0.005 & 0.001 & -3.782 & 0.000 & -0.001 & 0.003 & -0.282 & 0.778 \\
\hline CountryBG & -0.002 & 0.001 & -1.496 & 0.135 & -0.001 & 0.002 & -0.485 & 0.628 \\
\hline CountryCZ & -0.018 & 0.002 & -11.018 & 0.000 & -0.011 & 0.003 & -3.504 & 0.000 \\
\hline CountryDE & -0.002 & 0.002 & -0.695 & 0.487 & -0.008 & 0.005 & -1.596 & 0.110 \\
\hline CountryDK & -0.012 & 0.003 & -4.536 & 0.000 & -0.045 & 0.005 & -8.376 & 0.000 \\
\hline CountryEE & -0.004 & 0.001 & -3.153 & 0.002 & -0.004 & 0.002 & -1.758 & 0.079 \\
\hline CountryES & -0.021 & 0.002 & -10.220 & 0.000 & -0.023 & 0.004 & -5.587 & 0.000 \\
\hline CountryFI & -0.009 & 0.002 & -5.889 & 0.000 & -0.014 & 0.003 & -4.470 & 0.000 \\
\hline CountryFR & -0.010 & 0.003 & -2.739 & 0.006 & -0.055 & 0.007 & -7.786 & 0.000 \\
\hline CountryGB & -0.005 & 0.003 & -1.687 & 0.092 & -0.031 & 0.006 & -5.653 & 0.000 \\
\hline CountryGR & -0.006 & 0.001 & -4.523 & 0.000 & -0.012 & 0.002 & -4.778 & 0.000 \\
\hline CountryHU & -0.003 & 0.001 & -2.497 & 0.013 & -0.008 & 0.003 & -3.204 & 0.001 \\
\hline CountryIE & -0.001 & 0.001 & -0.817 & 0.414 & -0.009 & 0.003 & -3.448 & 0.001 \\
\hline CountryIT & -0.011 & 0.002 & -5.135 & 0.000 & -0.038 & 0.004 & -9.258 & 0.000 \\
\hline CountryLI & -0.014 & 0.001 & -11.326 & 0.000 & -0.006 & 0.002 & -2.602 & 0.009 \\
\hline CountryLT & -0.001 & 0.001 & -0.807 & 0.419 & -0.007 & 0.002 & -2.922 & 0.003 \\
\hline CountryLU & -0.001 & 0.001 & -1.013 & 0.311 & -0.005 & 0.002 & -2.016 & 0.044 \\
\hline CountryLV & -0.006 & 0.001 & -5.045 & 0.000 & -0.004 & 0.002 & -1.645 & 0.100 \\
\hline CountryNL & -0.000 & 0.002 & -0.028 & 0.978 & -0.017 & 0.004 & -4.329 & 0.000 \\
\hline CountryPL & -0.006 & 0.002 & -4.077 & 0.000 & -0.004 & 0.003 & -1.357 & 0.175 \\
\hline CountryPT & -0.006 & 0.001 & -4.355 & 0.000 & -0.003 & 0.003 & -0.980 & 0.327 \\
\hline CountryRO & -0.000 & 0.001 & -0.186 & 0.852 & -0.021 & 0.003 & -7.698 & 0.000 \\
\hline CountrySE & -0.001 & 0.001 & -0.429 & 0.668 & -0.007 & 0.003 & -2.383 & 0.017 \\
\hline CountrySI & -0.003 & 0.001 & -2.593 & 0.010 & -0.005 & 0.002 & -2.181 & 0.029 \\
\hline CountrySK & -0.007 & 0.001 & -4.692 & 0.000 & -0.012 & 0.003 & -4.183 & 0.000 \\
\hline Degree & -0.028 & 0.001 & -24.494 & 0.000 & -0.001 & 0.002 & -0.431 & 0.666 \\
\hline Density & -0.103 & 0.001 & -70.933 & 0.000 & -0.076 & 0.003 & -25.839 & 0.000 \\
\hline elece & -0.725 & 0.004 & -189.184 & 0.000 & -0.221 & 0.008 & -28.522 & 0.000 \\
\hline Emissions & -0.007 & 0.003 & -2.548 & 0.011 & -0.000 & 0.005 & -0.087 & 0.931 \\
\hline Finance & -0.008 & 0.006 & -1.385 & 0.166 & -0.015 & 0.012 & -1.252 & 0.210 \\
\hline Industry & -0.013 & 0.006 & -2.170 & 0.030 & -0.020 & 0.012 & -1.627 & 0.104 \\
\hline Intercept & -0.000 & 0.001 & -0.000 & 1.000 & -0.000 & 0.002 & -0.000 & 1.000 \\
\hline news & -0.009 & 0.001 & -8.243 & 0.000 & -0.032 & 0.002 & -13.959 & 0.000 \\
\hline ngase & -0.087 & 0.002 & -45.285 & 0.000 & -0.098 & 0.004 & -25.389 & 0.000 \\
\hline Tempext5 & -0.013 & 0.002 & -7.974 & 0.000 & -0.052 & 0.003 & -16.174 & 0.000 \\
\hline Tempext95 & -0.006 & 0.002 & -3.810 & 0.000 & -0.033 & 0.003 & -10.464 & 0.000 \\
\hline Tradeperiod1 & -0.546 & 0.004 & -148.822 & 0.000 & -0.587 & 0.007 & -78.931 & 0.000 \\
\hline Tradeperiod2 & -0.189 & 0.004 & -52.746 & 0.000 & -0.721 & 0.007 & -99.364 & 0.000 \\
\hline Tradeperiod3 & -0.268 & 0.002 & -110.397 & 0.000 & -0.587 & 0.005 & -119.524 & 0.000 \\
\hline Tradeperiod 4 & -0.286 & 0.003 & -87.584 & 0.000 & -0.227 & 0.007 & -34.277 & 0.000 \\
\hline Tradeperiod5 & -0.081 & 0.002 & -46.386 & 0.000 & -0.093 & 0.004 & -26.283 & 0.000 \\
\hline Volume & -0.002 & 0.001 & -1.567 & 0.117 & -0.003 & 0.002 & -1.305 & 0.192 \\
\hline
\end{tabular}

As far as energy and abatement variables are concerned, we observe negative coefficients for the Clean Dark Spread and the price of the $\mathrm{CO} 2$ intensive fuel coal, and a positive coefficient for the Clean Spark Spread. This can be explained by the switching behavior of electricity producers. A higher level of coal prices increases incentives to switch to less emission intensive natural gas, bringing demand and prices for emission certificates down. The positive sign of the coefficient for electricity prices is in line with these theoretical considerations. The negative coefficient for natural gas in contrast is counter intuitive. The positive sign of the Volume coefficient indicates that an elevated trading activity in terms of the number of traded certificates slightly increases EUA prices.

As far as the weather variables are concerned we observe negative and significant coefficients in all three cases (avgtemp, Tempext5 and Tempext95): Higher average temperatures might decrease the demand for electricity, especially in countries 


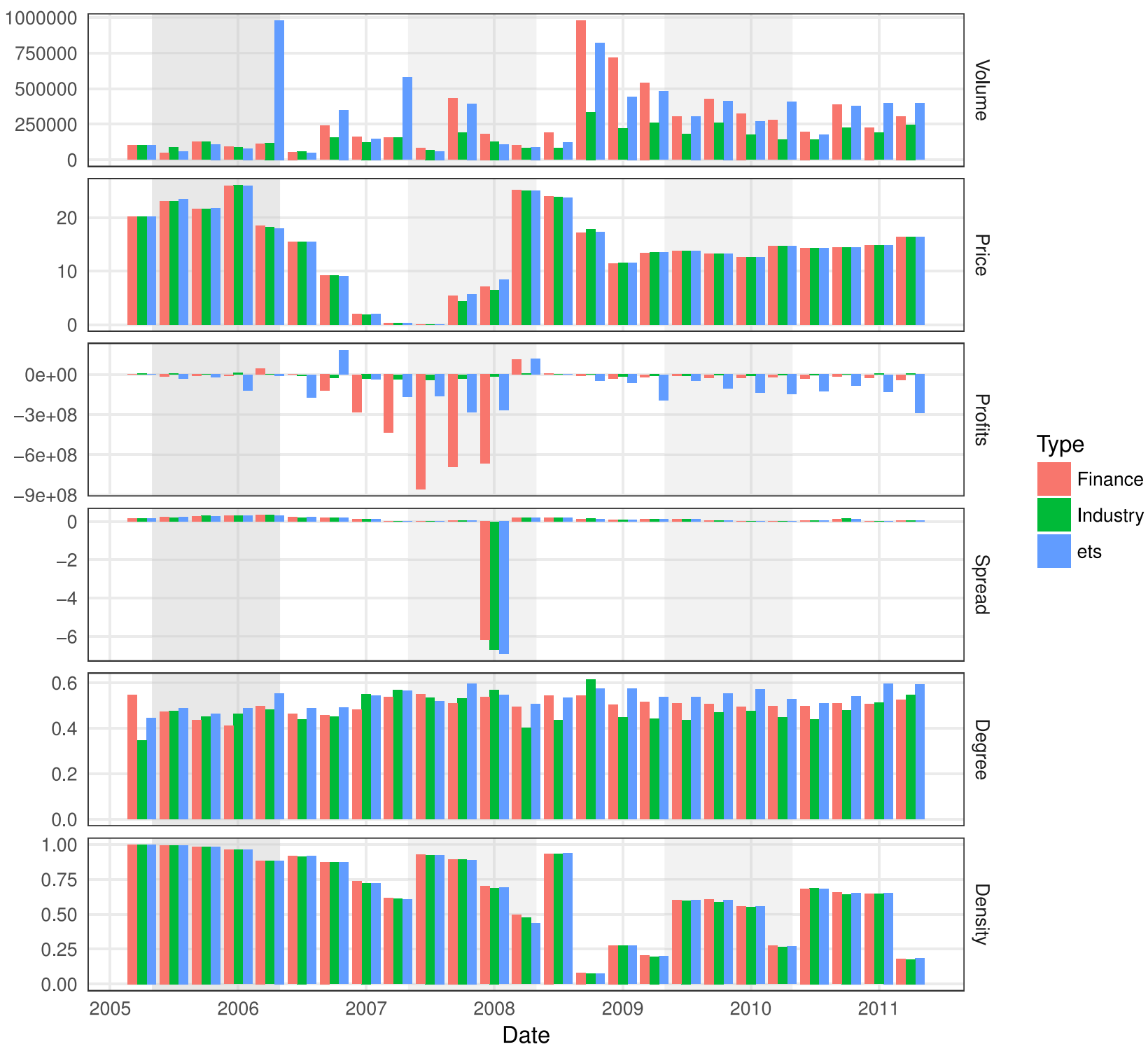

Fig. 8. Evolution of synthetic network metrics (finance: red, industry: green, average: blue). (For interpretation of the references to color in this figure legend, the reader is referred to the web version of this article.)

with widespread electrical heating, and thus have a negative effect of EUA prices. Extreme weather phenomena dampen economic activity in general, and thus have a negative effect on the demand for EUAs.

\subsubsection{Bid-ask spread}

The bid-ask spread is, as mentioned before, often interpreted as a measure for informational asymmetry or trading frictions in the market: the difference between the buyer and seller price is assumed to reflect diverging degrees of informedness about the true market price (see Medina et al., 2014, in this respect). It is thus not surprising that an elevated difference between buyer and seller degree, is reflected in diverging ideas about pricing and thus an increased bid-ask spread. The corresponding coefficient in the inner model equation for the bid-ask spread is thus slightly positive and significant. Density in the context can also be interpreted as a proxy for information: the denser (more complete) a network is, the more agents have traded in the market in the past (within the window size) and the better and more alike their level of information is, over which they dispose when concluding a transaction. When the trading network exhibits a higher density, we would thus expect an on average lower bid-ask spread. The negative and significant coefficient for this variable is in line with this interpretation.

The interpretation of the abatement and energy coefficient in the context of the bid-ask spread equation is a bit more involved. We observe that the coefficients behave similar as in the price equation. The only difference is that the coefficient 

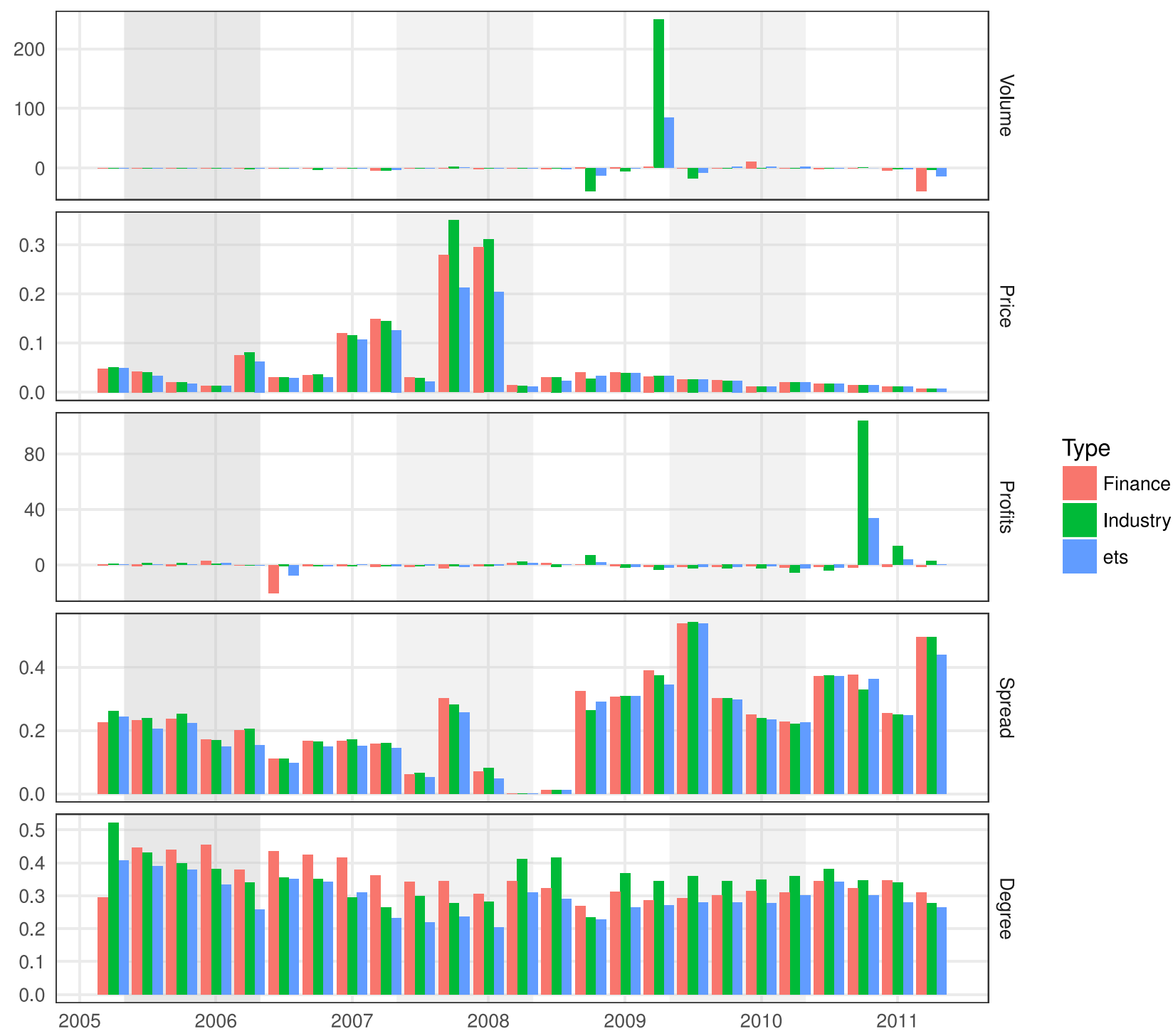

Date

Fig. 9. Evolution of Gini coefficients of synthetic network metrics (finance: red, industry: green, average: blue). (For interpretation of the references to color in this figure legend, the reader is referred to the web version of this article.)

for the natural gas price variable is positive. Following the principle idea of emission trading, OHAs with higher abatement costs are supposed to acquire their missing EUAs on the market rather than to make the costly investments necessary to bring down emissions by means of technologically upgrading their installations. Along this considerations a similar mechanism has to be at work as in the case of EUA prices. Higher/lower abatement costs might lead to an increased/decreased pressure of accepting asked prices thus reducing/increasing the bid-ask spread.

\subsection{Evolution of the emission trading network over time}

As underlined above, the weights estimated in the outer model of the PLS-PM estimation can be used to construct synthetic network measures, without knowing the "correct" window size. These measures allow us to gain insights on how the topology of the emission trading network evolves and how the position of different subgroups within this network changes over time.

The interpretation of the different network metrics and of their Gini coefficients displayed respectively in Figs. 8 and 9 is complex. In general one can state that market efficiency has improved over time. As the share of spot market trading rose, it became easier for agents to aggregate information and to participate in the European emission market. This interpretation is backed by the decrease of the average and of the Gini coefficient of the variable measuring the difference between seller 
and buyer degrees. Simultaneously, we observe a higher market participation rate, which might have brought down the connectedness in the network. Indeed, the number of possible links grows exponentially with the number of new agents (nodes) in the network. This effect is most articulated in trade period four where the trading intensity in terms of volume traded was at one of the highest, while the connectedness (Density) in the trading network was at one of the lowest levels.

While above results indicate an overall improvement in market efficiency, a closer look at the differences in scores between the different types of agents reveals that some problematic aspects of the organization of the EU ETS persist. In fact, we observe an increasing gap towards the later periods for the degree seller buyer difference variable between agents of type "Finance" and agents of type "Industry". This implies a persistent asymmetry between industrial and financial actors as far as their relative network position is concerned. In contrast, the overall inequality in terms of market participation between these two types of agents, was thus in fact not decreasing but got more pronounced over time (see e.g., Volume variable in Table 8).

\section{Conclusion}

We have analyzed the European Emission trading system from a network perspective. Empirically, the transaction network is characterized by clustering behavior of agents, a fat tailed degree distribution and a pronounced hierarchical structure. A quantitative analysis of the drivers of link formation shows that the emergence of this structure is explained by the fact that agents had to resort to local networks and financial intermediaries to exchange emission certificates: transactions were driven by the need to identify a potential counterpart through geographical proximity or prominence in the network rather than by complementarity in marginal abatement costs.

The hierarchical structure of the network also suggests that central agents might have captured informational rents and thus influence on the price formation process as well as "abnormal" profits. In order to confirm this intuition we have performed an in-depth analysis of the joint evolution of network statistics and of key market characteristics (prices, bid-ask spread) using a Partial Least Square-Path Modeling technique. The results of this analysis confirms the impact of central agents on market dynamics. Over time, the overall efficiency of the market shows some signs of improvement though a strong asymmetry between industrial and financial actors as well as in overall remains.

In our opinion, these results reflect a major flaw in the organization of the European carbon market. Through the period under consideration, trading was largely performed through bilateral OTC transactions and industrial actors had to resort to local networks or financial intermediaries. Hence, the lack of an institutional structure of the market imposed unnecessary costs on industrial actors, which often do not possess the resources to collect market-related information. This undermines the key objective of the European Emission Trading System to reduce greenhouse gas emissions at the least possible cost.

Although the major flaws outlined above in principle still exist, market quality has improved over time with the increasing share of spot market trading. More broadly, a number of pathways towards a more efficient market can be highlighted, in particular through a comparison with the SO2 emission market that was put in place in the U.S in the early 1990s and is generally recognized as efficient (see e.g., Albrecht et al., 2006; Schmalensee and Stavins, 2013). A first potential solution to decrease transaction costs and informational asymmetries is the emergence of a central trading institution. Such a process might be a side effect of the expansion of auctioning of allowances, given that the EEX trading platform has a quasimonopoly on these auctions and is therefore likely to become a focal point for allowance trading. A converse approach to decrease transaction costs and informational asymmetries would be to foster competition in brokerage services on the carbon market. A comparison with the SO2 market indeed suggests that the supply of brokerage services and the information thereabout is much more important in the US SO2 market than in the EU ETS (see Sanin, 2012, and references therein). Additionally, a tightening of the emission cap might as well be an important stimulus to the efficiency of the market. Indeed, as emphasized by Burtraw (1996), in the case of the SO2 market, the move towards performance standard induced by the price pressure was sufficient to reduce massively both emissions and the costs of compliance. In this sense, an allowance trading program may not require much trading in order to be successful.

\section{Acknowledgments}

The authors acknowledge financial support from the Horizon 2020 research and innovation programme under grant agreement no. 640772 (DOLFINS).

\section{Appendix A. Maslov-Sneppen random rewiring}

A basic method within the class of approaches to investigate the formation process of a network is the Maslov-Sneppen (Maslov and Sneppen, 2002) algorithm: comparing the empirical network with a quantity of random networks with an identical degree sequence and distribution allows us to generate degree-degree correlation profiles which permit to identify connectivity patterns between nodes of different degrees. The so called null-model is generated by systematically rewiring the original network: Two pairs of connected nodes $A->B$ and $C->D$ are randomly selected from a network and rewired in the fashion $A->D$ and $C->B$. If the thereby generated new connections already exist the procedure is aborted and two new pairs of connected nodes are randomly selected and the rewiring attempt is repeated. Doing this sufficiently often, a rule of thumb suggests a number as high as ten times the number of edges, one obtains a random graph with the 
same degree sequence and distribution as the original graph. This procedure is repeated multiple times. Then the generated null-models are compared with the original network. More precisely, we compare the number of edges between two nodes with degrees $K_{1}$ and $K_{2}$ in the empirical network $N\left(K_{1}, K_{2}\right)$ and the mean in the generated random networks $\bar{N}_{r}\left(K_{1}, K_{2}\right): R\left(K_{1}, K_{2}\right)=N\left(K_{1}, K_{2}\right) / \bar{N}_{r}\left(K_{1}, K_{2}\right)$. If the deviance of the empirical network from the null-model is significant can be assessed by computing the Z-scores: $Z\left(K_{1}, K_{2}\right)=\left(N\left(K_{1}, K_{2}\right)-\bar{N}_{r}\left(K_{1}, K_{2}\right)\right) / \operatorname{sigma}\left(K_{1}, K_{2}\right)$, where sigma $\left(K_{1}, K_{2}\right)$ is the standard deviation of $\bar{N}_{r}\left(K_{1}, K_{2}\right)$.

\section{Appendix B. Network statistics}

1. Asymmetry: The Gini-coefficient of the degree distribution measuring the inequality or asymmetry of the connectivity of agents.

2. Degree centrality: Degree centrality measures the connectedness of a vertex. In a network with $n$ vertices a vertex can have at maximum a degree of $n-1$ (i.e., links to other nodes). The degree centrality measure is then the relation of the degree of one node $i$ to the number of all other nodes: $C e_{i}^{d}=d_{i}(g) /(n-1)$. This means the higher the centrality of one vertex with respect to its degree is, the closer to one this centrality measure will be. In the context of this study the graph-level degree centrality is used. The score is normalized by the maximum theoretical score for a graph with the same number of vertices.

3. Eigenvector centrality (Bonacich, 1987): This measure considers not only the connectedness of a vertex but also the connectedness of its neighbors. The centrality therefore not only depends on the links a vertex has but also on how central its neighbors are within the network. If $A$ is the adjacency matrix of the network $N$ where its elements $a_{i, j} \in\{0,1\}$ indicate the presence of a link ( 0 no link; 1 link) between two vertices $i$ and $j$, and $M(i)$ is the set of neighbors of vertex $i$, the eigenvector centrality of a vertex is the sum of the centralities of its neighbors multiplied by a constant $\frac{1}{\lambda}$ : $C_{i}^{e}=\frac{1}{\lambda} \sum_{j \in M(i)} C_{j}^{e}=\frac{1}{\lambda} \sum_{i \in N} a_{i, j} C_{j}^{e}$. Rearranged in matrix form one gets the eigenvector equation $A x=\lambda x$ which is eponymous for this centrality measure. In the context of this study the graph-level eigenvector centrality is used. The score is normalized by the maximum theoretical score for a graph with the same number of vertices.

4. PageRank centrality (Page et al., 1999): This centrality measure is a variety of the eigenvector centrality and represents the likelihood that an agent randomly selecting different links will arrive at any particular vertex.

5. Closeness centrality (Freeman, 1979): This centrality measure is defined as the inverse of the average shortest distance from one vertex to all other vertices. Thus if $l(i, j)$ is the number of links on the shortest path between the vertices $i$ and $j$, the average distance (number of links) is $d(i, j)=\sum_{i \neq j} l(i, j) /(n-1)$ and the closeness centrality measure is $C e_{i}^{c}=(n-1) / \sum_{i \neq j} l(i, j)=\sum_{i \neq j} 1 / d(i, j)$. In the context of this study the graph-level closeness centrality is used. The score is normalized by the maximum theoretical score for a graph with the same number of vertices.

6. Betweenness centrality (Freeman, 1979): In contrast to the degree and closeness centrality the betweenness centrality doesn't measure the centrality of a vertex by the connectedness of a vertex but rather by its role as an intermediator. The betweenness centrality of a vertex $i$ is thus the number of shortest paths between a pair of vertices $j$ and $k$ on which one can find vertex $i$ relative to the number of all shortest paths between $j$ and $k$ summed over all pairs of vertices. If $p_{j k}$ is the total number of paths between two vertices $j$ and $k$ and $p_{j k}(i)$ is the number of paths between these two vertices passing through vertex $i$, betweenness centrality is defined as: $C e_{i}^{b}=\sum_{i \neq j \neq k} p_{j k}(i) / p_{j k}$. In the context of this study the graph-level betweenness centrality is used. The score is normalized by the maximum theoretical score for a graph with the same number of vertices.

7. Clustering: This metric is sometimes also denoted as the clustering coefficient as it measures the probability that the adjacent vertices of a vertex are connected. In the node-level case the definition by Barrat et al. (2004) for the transitivity metric is $C_{i}^{w}=1 / s_{i}\left(k_{i}-1\right) \sum_{i, h}\left(w_{i j}+w_{i j}\right) / 2 a_{i j} a_{i h} a_{j h}$, where $s_{i}$ is the strength of a vertex, which is defined as the sum of edges of all adjacent vertices, $k_{i}$ is the degree of the vertex, $a_{i j}$ are elements of the adjacency matrix and $w_{i j}$ are the weights.

8. Katz Centrality (Katz, 1953): Katz centrality computes the relative centrality of a node within a network by measuring the number of neighbors and all other nodes in the network that connect to this respective node via its neighbors.

9. Density: Following Wasserman and Faust (1994) the density of a graph is defined as the ratio of the number of edges and the number of theoretically possible edges.

10. Power: The exponent of the power law distribution fitted to the degree distribution.

11. Assortativity: The preferential attachment with regard to type (industry, finance etc.), origin and connectedness. Be $e_{i} j$ the fraction of edges in a network which connect vertices of type $i$ and $j$. For undirected networks this value is symmetric: $e_{i j}=e_{j i}$. If $a_{i}$ and $b_{i}$ are the fractions for each type of target originating from a vertex of type $i$, this implies that $\sum_{i j} e_{i j}=$ $1, \sum_{j} e_{i j}=a_{i}$ and $\sum_{i} e_{i j}=b_{j}$. The assortative mixing score is then $\left(\sum_{i} e_{i i}-\sum_{i} a_{i} b_{1}\right) /\left(1-\sum_{i} a_{i} b_{i}\right)$.

\section{References}

Alberola, E., Chevallier, J., 2009. European carbon prices and banking restrictions: evidence from phase I (2005-2007). Energy J. 51-79.

Alberola, E., Chevallier, J., Chèze, B., 2008. Price drivers and structural breaks in European carbon prices 2005-2007. Energy Policy 36 (2), 787-797.

Albrecht, J., Verbeke, T., De Clercq, M., 2006. Informational efficiency of the $\mathrm{USSO}_{2}$ permit market. Environ. Model. Softw. 21 (10), $1471-1478$.

Banerjee, A., Chandrasekhar, A.G., Duflo, E., Jackson, M.O., 2013. The diffusion of microfinance. Science 341 (6144), 1236498. 
Barrat, A., Barthelemy, M., Pastor-Satorras, R., Vespignani, A., 2004. The architecture of complex weighted networks. In: Proceedings of the National Academy of Sciences of the United States of America, 101. National Academy of Sciences, pp. 3747-3752.

Battiston, S., Gatti, D.D., Gallegati, M., Greenwald, B., Stiglitz, J.E., 2012. Liaisons dangereuses: increasing connectivity, risk sharing, and systemic risk. J. Econ. Dyn. Control 36 (8), 1121-1141.

Battiston, S., Puliga, M., Kaushik, R., Tasca, P., Caldarelli, G., 2012. Debtrank: too central to fail? financial networks, the fed and systemic risk. Sci. Rep. 2.

Betz, R.A., Schmidt, T.S., 2016. Transfer patterns in phase I of the EU emissions trading system: a first reality check based on cluster analysis. Clim Policy 16 (4), 474-495

Bonacich, P., 1987. Power and centrality: a family of measures. Am. J. Sociol. 1170-1182.

Borghesi, S., Montini, M., 2016. The best (and worst) of GHG emission trading systems: comparing the EU ETS with its followers. Front. Energy Res. 4, 27.

Borovkov, K., Decrouez, G., Hinz, J., 2011. Jump-diffusion modeling in emission markets. Stochast. Models 27 (1), $50-76$.

Burtraw, D., 1996. The so2 emissions trading program: cost savings without allowance trades. Contemp. Econ. Policy 14 (2), $79-94$.

Carmona, R., Hinz, J., 2011. Risk-neutral models for emission allowance prices and option valuation. Manag. Sci. 57 (8), $1453-1468$.

CDC Climate Research, 2013. Methodology - Tendances Carbone. Paris. URL http://www.cdcclimat.com/IMG/pdf/methodologie_tendances_carbone_en_v8.pdf.

Charles, A., Darné, O., Fouilloux, J., 2013. Market efficiency in the European carbon markets. Energy Policy 60, 785-792.

Chevallier, J., 2011. Econometric Analysis of Carbon Markets: The European Union Emissions Trading Scheme and the Clean Development Mechanism. Springer Science \& Business Media.

Chevallier, J., Sévi, B., 2014. On the stochastic properties of carbon futures prices. Environ. Resour. Econ. 58 (1), 127-153.

Chinazzi, M., Fagiolo, G., Reyes, J.A., Schiavo, S., 2013. Post-mortem examination of the international financial network. J. Econ. Dyn. Control 37 (8), 1692-1713.

Convery, F., Ellerman, D., De Perthuis, C., 2008. The European carbon market in action: lessons from the first trading period. J. Eur. Environ. Plan. Law 5 (2), $215-233$.

Creti, A., Jouvet, P.-A., Mignon, V., 2012. Carbon price drivers: phase I versus phase ii equilibrium? Energy Econ. 34 (1), $327-334$

Duenas, M., Fagiolo, G., 2014. Global trade imbalances: a network approach. Adv. Complex Syst. 17 (03n04), 1450014.

EEA, 2015. Trends and Projections in the EU ETS in 2015. Technical Report. Copenhagen: European Environment Agency.

Ellerman, A.D., 2010. Pricing Carbon: the European Union Emissions Trading Scheme. Cambridge University Press.

Ellerman, A.D., Marcantonini, C., Zaklan, A., 2016. The European Union emissions trading system: ten years and counting. Rev. Environ. Econ. Policy 10 (1), 89-107.

Engels, A., 2009. The European emissions trading scheme: an exploratory study of how companies learn to account for carbon. Account. Organ. Soc. 34 (3), $488-498$.

European-Commission, 2015. EU-ETS Handbook.

Firgo, M., Pennerstorfer, D., Weiss, C.R., 2015. Centrality and pricing in spatially differentiated markets: the case of gasoline. Int. J. Ind. Organ. 40, 81-90.

Freeman, L.C., 1979. Centrality in social networks conceptual clarification. Soc. Netw. 1 (3), 215-239.

Frunza, M.-C., Guegan, D., Lassoudiere, A., 2011. Missing trader fraud on the emissions market. J. Financ. Crime 18 (2), $183-194$.

Gualdi, S., Mandel, A., 2016. On the emergence of scale-free production networks. J. Econ. Dyn. Control 73, 61-77.

Gullberg, A.T., 2008. Lobbying friends and foes in climate policy: the case of business and environmental interest groups in the European Union. Energy Policy 36 (8), 2964-2972.

Handcock, M. S., Hunter, D. R., Butts, C. T., Goodreau, S. M., Morris, M., 2003. Statnet: Software tools for the Statistical Modeling of Network Data. Seattle, WA. URL http://statnetproject.org.

Helfand, G.E., Moore, M.R., Liu, Y., 2006. Testing for Dynamic Efficiency of the Sulfur Dioxide Allowance Market. University of Michigan WP.

Hepburn, C., Grubb, M., Neuhoff, K., Matthes, F., Tse, M., 2006. Auctioning of EUETS phase II allowances: how and why? Clim. Policy 6 (1), 137-160.

Hintermann, B., 2010. Allowance price drivers in the first phase of the EU ETS. J. Environ. Econ. Manag. 59 (1), 43-56.

Hintermann, B., Peterson, S., Rickels, W., 2015. Price and market behavior in phase II of the EUETS: a review of the literature. Rev. Environ. Econ. Policy 10 (1), 108-128.

Howison, S., Schwarz, D., 2012. Risk-neutral pricing of financial instruments in emission markets: a structural approach. SIAM J. Financ. Math. 3 (1), 709-739.

Iori, G., De Masi, G., Precup, O.V., Gabbi, G., Caldarelli, G., 2008. A network analysis of the Italian overnight money market. J. Econ. Dyn. Control 32 (1), $259-278$

Jaraitè, J., Jong, T., Kažukauskas, A., Zaklan, A., Zeitlberger, A., 2013. Matching EU ETS Accounts to Historical Parent Companies: A Technical Note. European University Institute Working Paper Series. Available online at http://fsr.eui.eu/CPRU/EUTLTransactionData.aspx.

Jaraite, J., Kažukauskas, A., et al., 2012. Firm Trading Behaviour and Transaction Costs in the European Union's Emission Trading System: An Empirical Assessment. Technical Report. CERE-the Center for Environmental and Resource Economics.

Katz, L., 1953. A new status index derived from sociometric analysis. Psychometrika 18 (1), 39-43.

Koch, N., Fuss, S., Grosjean, G., Edenhofer, O., 2014. Causes of the EU ETS price drop: recession, DM, renewable policies or a bit of everything?-new evidence. Energy Policy 73, 676-685.

Kossinets, G., Watts, D.J., 2006. Empirical analysis of an evolving social network. Science 311 (5757), 88-90.

Laing, T., Sato, M., Grubb, M., Comberti, C., et al., 2013. Assessing the Effectiveness of the EUEmissions Trading System. Grantham Research Institute on Climate Change and the Environment. Working Paper 106.

Li, D. and Schürhoff, N., 2014. Dealer Networks. FEDS Working Paper No. 2014-95.

Martin, R., Muûls, M., Wagner, U. J., 2014. Trading behavior in the EU emissions trading scheme. Available at SSRN 2362810.

Martin, R., Muûls, M., Wagner, U.J., 2015. The impact of the European union emissions trading scheme on regulated firms: what is the evidence after ten years? Rev. Environ. Econ. Policy 10 (1), 129-148.

Maslov, S., Sneppen, K., 2002. Specificity and stability in topology of protein networks. Science 296 (5569), $910-913$.

Medina, V., Pardo, Á., Pascual, R., 2014. The timeline of trading frictions in the European carbon market. Energy Econ. 42, $378-394$.

Page, L., Brin, S., Motwani, R., \& Winograd, T. (1999). The PageRank citation ranking: Bringing order to the web. Stanford InfoLab.

Palao, F., Pardo, A., 2012. Assessing price clustering in European carbon markets. Appl Energy 92, 51-56.

Panzarasa, P., Opsahl, T., Carley, K.M., 2009. Patterns and dynamics of users' behavior and interaction: network analysis of an online community. J. Am. Soc. Inf. Sci. Technol. 60 (5), 911-932.

Puliga, M., Caldarelli, G., Battiston, S., 2014. Credit default swaps networks and systemic risk. Sci. Rep. 4.

Sanin, E., 2012. Designing pollution markets. Reflets et perspectives de la vie économique 51 (3), 143-159.

Sapio, S., Kirman, A., Dosi, G., 2011. The emergence and impact of market institutions: the wholesale market for fish and other perishable commodities. J Econ. Behav. Org. 1 (80), 1-5.

Schmalensee, R., Stavins, R.N., 2013. The $\mathrm{SO}_{2}$ allowance trading system: the ironic history of a grand policy experiment. J. Econ. Perspect. 27 (1), $103-121$.

Sijm, J., Neuhoff, K., Chen, Y., 2006. $\mathrm{Co}_{2}$ cost pass-through and windfall profits in the power sector. Clim. policy 6 (1), $49-72$.

Stavins, R.N., 1995. Transaction costs and tradeable permits. J. Environ. Econ. Manag. 29 (2), 133-148.

Valente, T.W., Coronges, K., Lakon, C., Costenbader, E., 2008. How correlated are network centrality measures? Connections 28 (1), 16.

Vignes, A., Etienne, J.-M., 2011. Price formation on the marseille fish market: evidence from a network analysis. J. Econ. Behav. Org. 80 (1), 50-67.

Wasserman, S., Faust, K., 1994. Social Network Analysis: Methods and Applications, 8. Cambridge University Press.

Zaklan, A., 2013. Why Do Emitters Trade Carbon Permits? Firm-Level Evidence from the European Emission Trading Scheme. Technical Report. DIW Berlin, German Institute for Economic Research. 
Zeileis, A., Kleiber, C., Krämer, W., Hornik, K., 2003. Testing and dating of structural changes in practice. Comput. Stat. Data Anal. 44 (1), $109-123$.

Zhu, B., Chevallier, J., 2017. Pricing and Forecasting Carbon Markets. Springer.

Zhu, B., Chevallier, J., Ma, S., Wei, Y., 2015. Examining the structural changes of European carbon futures price 2005-2012. Appl. Econ. Lett. 22 (5), 335-342. doi:10.1080/13504851.2014.943875.

Zhu, B., Ma, S., Chevallier, J., Wei, Y.-M., 2014. Modelling the dynamics of European carbon futures price: a zipf analysis. Econ. Model. 38 (C), $372-380$.

Zhu, B., Wang, P., Chevallier, J., Wei, Y., 2015. Carbon price analysis using empirical mode decomposition. Comput. Econ. 45 (2), 195-206. 